\title{
Exergy and energy amelioration for parabolic trough collector using mono and hybrid nanofluids
}

\author{
Otabeh Al-Oran $^{1,2}$ (1) $\cdot$ Ferenc Lezsovits $^{1} \cdot$ Ayham Aljawabrah $^{1}$
}

Received: 12 September 2019 / Accepted: 20 January 2020 / Published online: 6 February 2020

(c) The Author(s) 2020

\begin{abstract}
Energy and exergy efficiency amelioration of the parabolic trough has taken high interest since recent years, especially when nanofluid used as an enhancement category. This paper aimed to improve LS-2 parabolic trough model and compare the enhancement effect that occurred using different mono and hybrid nanofluids. Inserting mono nanoparticles of $\mathrm{Al}_{2} \mathrm{O}_{3}$, $\mathrm{CeO}_{2}, \mathrm{CuO}$, and hybrid combinations of $\mathrm{Al}_{2} \mathrm{O}_{3}$ with $\mathrm{CeO}_{2}$, or $\mathrm{CuO}$ nanoparticles in a Syltherm 800 was investigated by five different cases. The investigation was presented under total volume fraction $4 \%$ for all nanofluids and mixing fraction 50:50 for the hybrid types in order to facilitate the analysis and compare various results at the same conditions. Those cases and their comparisons were solved using MATLAB Symbolic tools under turbulent flow regime and variable inlet temperature to present wide domain behavior for the energy and exergy efficiency, Nusselt number, heat transfer coefficient, and pressure drop, whereas the analytical solution of the energy balance equation was taken from the literature and improved to cover the mentioned cases. Moreover, the results were compared with previous researches that used different thermal fluid and showed high accuracy behavior with low deviation. Therefore, the findings showed that $\mathrm{Al}_{2} \mathrm{O}_{3}$ and $\mathrm{CeO}_{2}$ hybrid nanofluids were more efficient than using of both $\mathrm{Al}_{2} \mathrm{O}_{3}$ and $\mathrm{CuO}$ hybrid nanofluids and any mono nanofluids contain the same nanoparticles. The maximum enhancement of thermal and exergy efficiency of using $\mathrm{Al}_{2} \mathrm{O}_{3}$ and $\mathrm{CeO}_{2}$ hybrid nanofluids was $1.09 \%$ and $1.03 \%$, respectively, whereas it was enhanced by $167.8 \%$ and $200.7 \%$ for the Nusselt number and heat transfer coefficient, respectively. Also, the hybrid nanofluids have higher advantage over the mono nanofluids by presenting lower pressure drop values. Finally, the assessment of efficiency variation affected by thermal properties of the nanoparticle was presented under optimum temperature equal to $575 \mathrm{~K}$.
\end{abstract}

Keywords Parabolic trough collector $\cdot$ Thermal performance enhancement $\cdot$ Hybrid nanofluid $\cdot$ Mono nanofluid $\cdot$ Thermal efficiency $\cdot$ Exergy efficiency

\begin{tabular}{ll}
\multicolumn{2}{l}{ List of symbols } \\
$A$ & Area $\left(\mathrm{m}^{2}\right)$ \\
$C$ & Concentration ratio $(-)$ \\
$C_{\mathrm{p}}$ & Specific heat capacity $\left(\mathrm{J} \mathrm{kg}^{-1} \mathrm{~K}^{-1}\right)$ \\
$D$ & Diameter (m) \\
$F$ & Focal length (m) \\
$f_{\mathrm{r}}$ & Friction factor $(-)$ \\
$G_{\mathrm{b}}$ & Solar beam intensity $\left(\mathrm{W} \mathrm{m}^{-2}\right)$ \\
$h$ & Heat transfer coefficient $\left(\mathrm{W} \mathrm{m}^{-2} \mathrm{~K}^{-1}\right)$
\end{tabular}

Otabeh Al-Oran

aloran@energia.bme.hu

1 Department of Energy Engineering, Faculty of Mechanical Engineering, Budapest University of Technology and Economics, Muegyetem rkp. 3, Budapest 1111, Hungary

2 Mechanical Engineering Department, The University of Jordan, Amman 11942, Jordan

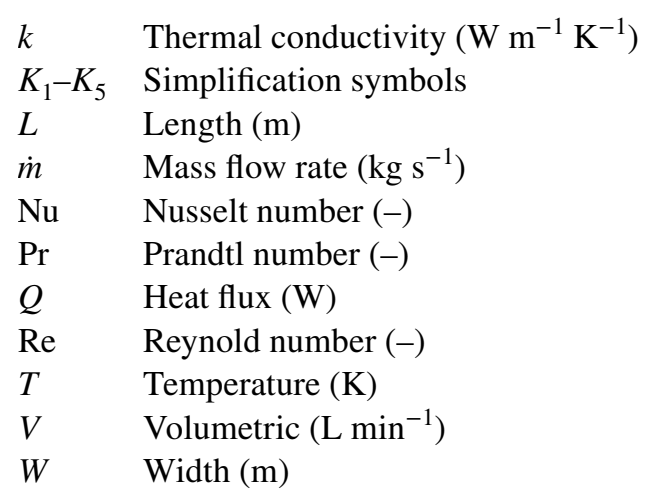

\section{Greek letters}

$\alpha \quad$ Absorptivity volume fraction

$\Gamma \quad$ Intercept factor

$\Delta p \quad$ Pressure drop

$\varepsilon \quad$ Emittance

$\eta \quad$ Efficiency (\%) 


$\begin{array}{ll}\theta & \text { Incident angle }\left(^{\circ}\right) \\ \mu & \text { Dynamic viscosity (pa s) } \\ P & \text { Density }\left(\mathrm{kg} \mathrm{m}^{-3}\right) \\ \rho_{\mathrm{c}} & \text { Reflectivity }(-) \\ \sigma & \text { Stefan-Boltzmann constant }=5.67 \times 10^{-8}\left(\mathrm{~W} \mathrm{~m}^{-2}\right. \\ & \left.\mathrm{K}^{-4}\right)\end{array}$

\section{Subscripts}

$\begin{array}{ll}\text { a } & \text { Aperture } \\ \text { am } & \text { Ambient } \\ \text { b } & \text { Beam } \\ \text { bf } & \text { Base fluid } \\ \text { c } & \text { Glass cover } \\ \text { ci } & \text { Glasses cover inner } \\ \text { co } & \text { Glass cover outer } \\ \text { eff } & \text { Thermal efficiency } \\ \text { ex } & \text { Exergy efficiency } \\ \text { flow } & \text { Flow rate } \\ \text { fm } & \text { Mean fluid } \\ \text { in } & \text { Inlet } \\ \text { loss } & \text { Losses } \\ \text { nf } & \text { Nanofluid } \\ \text { np } & \text { Nanoparticle } \\ \text { opt } & \text { Optical } \\ \text { out } & \text { Outlet } \\ \text { r } & \text { Absorber } \\ \text { ri } & \text { Absorber inner } \\ \text { ro } & \text { Absorber outer } \\ \text { s } & \text { Sensible } \\ \text { sun } & \text { Sun } \\ \text { tot } & \text { Total } \\ \text { u } & \text { Useful } \\ \text { Abbreviations } \\ \text { CFD } & \text { Computational fluid dynamic } \\ \text { EG } & \text { Ethylene glycol } \\ \text { FPC } & \text { Flat plate collector } \\ \text { HNF } & \text { Hybrid nanofluid } \\ \text { PTC } & \text { Parabolic trough collector } \\ \text { SNL } & \text { Sandia National Laboratories } \\ \text { TF } & \text { Thermal fluid } \\ & \end{array}$

\section{Introduction}

High degradation of fossil fuel levels has become an issue in the new era because of the high increase in the demand. The increasing demand, ascending electricity cost, and environmental issues of the pollutant emissions that have been produced from combustion processes of fusel fuel forced the government and researchers to find efficient ways to replace fossil energy with renewable and clean energy [1]. Alternative energy sources have been used in recent years as solar, wind, geothermal, or biomass energies, which in turn have a great impact to minimize pollution's effect and inadequate fossil fuel [2, 3]. Renewable resource such as solar energy is available and does not need a transportation medium. Also, solar energy can be designed to meet the requirements of power demands, and it can be worked in conjunction with diesel generators or any other power sources in order to provide such a continuous and stable power $[4,5]$. Many researchers have been conducted studies on solar energy concentrating on the capability of producing energy from solar radiation intensity and get benefit from both sides of economic effects, the consequences of solar energy synchronizing with other direct and indirect applications such as heating [6], refrigeration and air-conditioning [7], and chemical industrial process [8].

In fact, parabolic trough collector (PTC) is considered one of the most typical solar power devices which has been used widely to produce high and medium temperatures coinciding with high efficiencies. The first appearance of PTC was in 1870 when Johan Ericsson designed a parabolic collector called a direct steam generator with $3.25 \mathrm{~m}^{2}$ (area) to produce power with a value of $373 \mathrm{~W}$ [9]. Accordingly, many types of research have been done regarding PTC, considering mainly the geometry, optical competence, and heat transfer enhancement which have been summarized in several review papers such as Havez et al. [10]. Havez et al. [10] summarized full details of the previous works between 1981 and 2016 for both experimental and numerical studies. Heat transfer enhancement was examined by using a small additive particle with numerous values of diameter in a nanoscale "nanoparticle." It showed such a good enhancement's effect especially during the process of mixing nanoparticle with various types of base fluids to produce a new thermal fluid called "nanofluid" $[11,12]$. The criteria of using nanofluid showed a rapid increase in using these types of modified fluids in multi-applications as shown clearly through the huge number of researches that were stored in Scopus data of scientific magazine [13]. For instance, in 2017 around 2425 papers discuss the nanofluid phenomena and about 76 papers of the total number interested in the "Hybrid nanofluid" topic [13]. Mahian et al. [14, 15] explained in their precious review paper (which is divided into two parts) an interesting method of nanofluid flow modeling in detail. Part one mainly talked about the main forces which affect the resulting suspensions, main thermal properties resulted from the correlations, and the physical approach model in case of single- and two-phase flows [14]. On the other hand, part two presented a computational technique to solve the transport equation of nanofluid flow under various regimes to cover and to predict the enhancement effect of using the proposal mixture [15]. Different types of metallic and nonmetallic nanoparticles were inserted in various base fluid types under either volume average or mass average concentrations. In fact, aluminum oxide $\left(\mathrm{Al}_{2} \mathrm{O}_{3}\right)$ is considered as the widely used nanoparticles 
in the literature where $41 \%$ of the researches used this type to enhance the thermal performance of PTC, while other types of nanoparticles $\left(\mathrm{CuO}, \mathrm{TiO}_{2}, \mathrm{Fe}_{2} \mathrm{O}_{3}\right.$, etc.) showed lower interests for the researchers as mentioned in Olia et al. [16], in their review. Furthermore, the aluminum oxide was examined with various base fluids like water [17], Syltherm 800 [18], and Therminol VP-1 [19].

Mwesigy et al. [20, 21] simulated a computational fluid dynamic (CFD) model to obtain the enhancement produced from inserting $\mathrm{CuO}$ nanoparticle in Syltherm 800 and $\mathrm{Cu}$ nanoparticle in Therminol VP-1, inside the receiver tube of the PTC under nonuniform heat flux distribution boundary conditions. The results showed that thermal enhancement reaches $15 \%$ for $\mathrm{CuO}$-Syltherm 800 and $12.5 \%$ for $\mathrm{Cu}-$ Therminol-VP1. Coccia et al. [22] construct their research on test numerous numbers of nanoparticles, namely $\mathrm{Fe} 2 \mathrm{O} 3$, $\mathrm{SiO}_{2}, \mathrm{TiO}_{2}, \mathrm{ZnO}, \mathrm{Al}_{2} \mathrm{O}_{3}$, and $\mathrm{Au}$. These nanoparticles were incorporated in water to generate various nanofluids under low and high concentration. The obtained results were unexpected because they reported a small enhancement at low volume concentrations and no effect at high concentrations. On the other hand, Bellos and Tzivanidis [23] stated a disparity on the improvements of the recorded thermal efficiency according to the insertion of $\mathrm{Al}_{2} \mathrm{O}_{3}, \mathrm{Fe}_{2} \mathrm{O}_{3}, \mathrm{Cu}$, $\mathrm{CuO}, \mathrm{SiO}_{2}$, and $\mathrm{TiO}_{2}$ in a Syltherm 800 as base fluid. The simulated results recorded a maximum enhancement of $0.74 \%$ using $\mathrm{Cu}$ under concentration of $6 \%$ compared with other nanofluids. Ghesemi and Ranjbar [17] simulated a CFD model to compare the thermal behavior of inserting $\mathrm{CuO}$ and $\mathrm{Al}_{2} \mathrm{O}_{3}$ nanoparticle with water at the volume fraction 3\%. The results reported enhancement in heat transfer coefficient of $28 \%$ and $35 \%$, respectively, at the same concentration. Subramani et al. [24] examined the improvement results that occurred in the thermal efficiency and heat transfer coefficient using nanofluid of $\mathrm{TiO}_{2}$ with ionized water in the PTC. The measured results were obtained for concentrations $0.05,0.1,0.2,0.5 \%$ and variable mass flow rate under turbulent conditions. Besides, the results were built based on the tested experimental thermophysical properties showing thermal efficiency enhancement up to $8.66 \%$ at $0.2 \%$ and $0.0667 \mathrm{~kg} \mathrm{~s}^{-1}$ for volume fraction and mass flow rate, respectively.

In fact, the obtained enhancement by using mono nanofluid has supported the researches in these fields to find a way to minimize the cost side by side with the increase in thermal performance. Mixing two or more nanoparticles with various base fluids called "hybrid nanofluid" (HNF) has appeared clearly in different applications because the improvement results occurred in the thermal properties [25]. The literature survey showed an increase in the research number related to predicting thermal properties, enhance stability, main challenges, and application that used HNF as an improvement method [26]. Suresh et al. [27-29] examined
HNF of inserting $\mathrm{Al}_{2} \mathrm{O}_{3}-\mathrm{Cu}$ with a base fluid of water in a three separately researches. These researches studied the following: first, preparing the HNF and, second, reporting the experimental results of thermal conductivity and the viscosity under variable volume fraction $(0.1,0.33,0.75,1$, and $2 \%$ ) for the fraction mass nanopowder $90: 10$ for $\mathrm{Al}_{2} \mathrm{O}_{3}$ and $\mathrm{Cu}$ [27]. Second and third researches investigated a friction factor and Nusselt number under turbulent and laminar flow for the same HNF under constant volume concentration equal $0.1 \%[28,29]$. The resulted HNF from mixing binary base fluid of water/ethylene glycol (EG) with a variable mixture ratio of hybrid nanoparticle of $\mathrm{TiO}_{2}-\mathrm{SiO}_{2}$ was examined under the turbulent regime by Hamid et al. [30]. They showed enhancement on heat transfer by $35.32 \%$ at the mixture ratio 40:60 for the $\mathrm{TiO}_{2}$ and $\mathrm{SiO}_{2}$, respectively, under high temperature of the experimental condition $70{ }^{\circ} \mathrm{C}$ [30]. Therefore, these promising enhancement results support researchers to use this type in the solar application. Unfortunately, the researches on using HNF in the solar application are limited, particularly, in the PTC. There are few researches that used HNF as an enhancement method, as shown later.

Bellos and Tzivanidis [31] compared the variation of the enhancement from using mono and HNF. In their research, they obtained enhancement less than hybrid, when they used $3 \%$ of $\mathrm{Al}_{2} \mathrm{O}_{3}$ or $3 \%$ of $\mathrm{TiO}_{2}$ with Syltherm 800 as a mono nanofluid. The output of simulation was developed using Engineering Equation Solver Software and based on the different correlation from the literature which showed enhancement in the thermal efficiency by $1.8 \%$ compared with mono nanofluids which showed only $0.7 \%$ [31]. Minea and Maghlany [32] reported the main heat transfer performance enhancement generated from mono and HNF in different applications. In addition, they explained deeply the main research findings of new nanofluid mixing type "HNF" in several aspects such as thermal conductivity, viscosity, Nusselt number, and the main correlations that covered the results which depend on various conditions for different literature surveys like concentration and temperature. Finally, the authors exhibited the simulation results of Nusselt number and thermal efficiency in a PTC application under laminar flow regime for the $\mathrm{HNF}$ of $\mathrm{Ag}-\mathrm{MgO}$ (with water) and $\mathrm{GO} / \mathrm{Co}_{3} \mathrm{O}_{4}$ (with binary base fluid consist of $60 \% \mathrm{EG}$ and $40 \%$ water) under volume concentration $2 \%$ and 0.15 , respectively, for both HNF [32].

The use of HNF as a promising heating fluid provides a high enhancement effect as proven in the previous paragraph. Until the date, there are limited studies concentrated on using HNF in the PTC application as an enhancement method. This paper inserted new types of mono and HNF to be examined as an improved method of the heating fluid flow inside LS2 PTC model. Mono nanoparticles of $\mathrm{Al}_{2} \mathrm{O}_{3}$, $\mathrm{CeO}_{2}, \mathrm{CuO}$ and a hybrid combination of $\mathrm{Al}_{2} \mathrm{O}_{3}$ and $\mathrm{CeO}_{2}$, or 
$\mathrm{Al}_{2} \mathrm{O}_{3}$ and $\mathrm{CuO}$ were examined in a base fluid of Syltherm 800 and compared under total concentration volume 4\%, and mixing fraction 50:50 for the hybrid types. Mainly, the correlations that used to describe the thermal properties and heat transfer effect were taken from the literature and used in the energy balance equation and then solved analytically using MATLAB Symbolic code. Finally, all the results of the energy and exergy efficiency, heat transfer coefficient, and dimensionless Nusselt number for each case were presented and their enhancement results were measured accordingly for all cases.

The main contribution points of this research paper are:

- Inserting new different mono and hybrid nanofluids and examining their thermal behavior effects in the thermal performance of PTC. Aluminum oxide $\left(\mathrm{Al}_{2} \mathrm{O}_{3}\right)$, cerium oxide $\left(\mathrm{CeO}_{2}\right)$, and copper oxide $(\mathrm{CuO})$ will be inserted in Syltherm 800 separately to form mono nanofluids while aluminum oxide was mixed with cerium oxide or copper oxide to form the hybrid nanofluids. Actually, cerium oxide as a nanoparticle has limited research in the solar applications which was investigated experimentally in only two studies, where one of them in a PTC [33], while the other one in a flat plate collector (FPC) [34].

- A developed thermal model was analyzed and improved using MATLAB Symbolic toolbox. The thermal model is based on solving the analytical equation of the energy balance equation that was mentioned in the literature and improved to cover the effect of using new mono and hybrid nanofluids [35].

- Under optimum temperature, this research presented the effect of the thermal properties for the nanoparticle on PTC thermal efficiency. This assessment aimed to define an efficient nanoparticle that enables PTC to reach higher efficiencies.

\section{Parabolic trough solar collector}

\section{Model specification}

Parabolic trough collector mainly consists of mirrors, receiver, structure, and tracking system. The mirrors were designed on parabola shape to convert and concentrated radiation rays on the heating collecting element to enhance the temperature of the TF as illustrated in Fig. 1. Receiver nowadays is covered with a glass envelope, coated with high absorptivity material, and evacuated. The purpose of using the evacuated receiver is to minimize heat losses and to improve heat transfer to TF flow inside the receiver.

For this research, we used LS2-PTC model to examine the thermal enhancement performance that occurred using hybrid and mono nanoparticles inserted in Syltherm 800 as

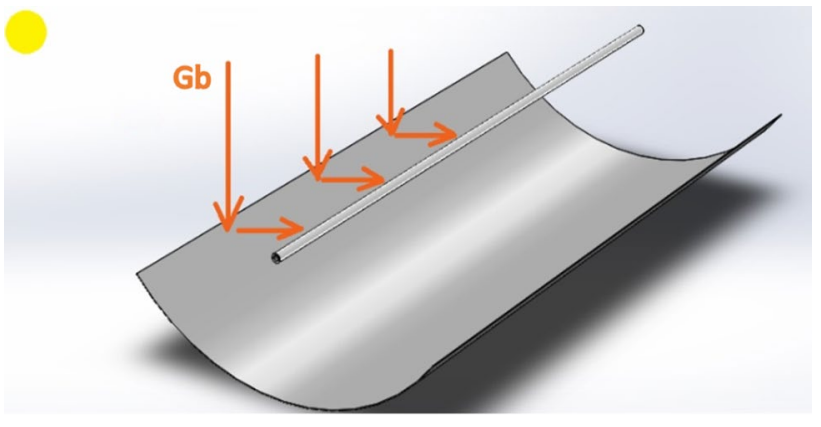

Fig. 1 PTC examined model schematic

base fluid, regarding the available experimental results for the same parabolic type and base fluid that allow to validate model [36]. The main dimensions and parameters conducted are described in Table 1 as mentioned in the literature [35]. A one-dimensional energy balance equation was improved using mono and HNF and then solved analytically using MATLAB Symbolic software. This simulation aimed to describe the enhancement occurred by different nanofluids and give a comparison between various mono and hybrid types under the same conditions. Table 2 presents the main cases that were covered in this research, where the constants and variables' conditions were presented, too.

\section{Thermal model}

This section aimed to describe the thermal model inside the receiver tube of the PTC by solving the energy balance equation at different nods. Through this section, the thermal resistance, heat losses, and heat transfer directions from thermal heating fluid to the cover had been presented. Studying the modes of heat transfer convection, radiation, and conduction at a different point from glass cover $(c)$ through absorber tube ( $r$ ) until reaching the TF was used to describe the gained heat from the system, as shown in Fig. 2.

As mentioned before, the analytical expression expressed by Bellos and Tzivanid [35] was used and improved using mono and HNF to cover the produced energy and exergy efficiency of the PTC so that the defined and simplified model was used and inserted in a MATLAB Symbolic code to cover a wide range of heating TF. The main assumptions that made in our research are: steady-state condition which referred to a constant heat flux due to the fluid flow inside the receiver tube because the length of pipe is lesser than $10 \mathrm{~m}$, the constant heat flux is in different sides, and the fluid is a turbulent flow.

Actually, the thermal model analytical expression was based on different points: First point defines the heat losses from the out-glass cover using Taylor series to make fourthorder temperature losses by radiation more simplified and then completes their simplification to define different heat 
Table 1 Parameters and main dimensions of PTC [35]

\begin{tabular}{llll}
\hline LS-2 parameter/symbols & Specifications & Parameter/symbols & Specifications \\
\hline Length of the PTC $/ L$ & $7.8 \mathrm{~m}$ & Emittance of glass cover $/ \varepsilon_{\mathrm{c}}$ & 0.9 \\
Aperture width of the PTC $/ W_{\mathrm{a}}$ & $5 \mathrm{~m}$ & Incident angle $/ \theta$ & 0 \\
Aperture area $/ A_{\mathrm{a}}$ & $39 \mathrm{~m}^{2}$ & Max optical efficiency $/ \eta_{\mathrm{opt}}$ & $74.5 \%$ \\
Focal length $/ F$ & $1.71 \mathrm{~m}$ & Glass cover absorbance $/ \alpha c$ & 0.02 \\
Concentration ratio/C & 22.74 & Glass cover transmittance $/ \tau_{\mathrm{c}}$ & 0.95 \\
Absorber inner diameter $/ d_{\mathrm{ri}}$ & $0.066 \mathrm{~m}$ & Absorber absorbance $/ \alpha_{\mathrm{r}}$ & 0.96 \\
Absorber outer diameter $/ d_{\mathrm{ro}}$ & $0.07 \mathrm{~m}$ & Concentrator reflectance $/ \rho_{\mathrm{c}}$ & 0.83 \\
Glass inner diameter $/ d_{\mathrm{ci}}$ & $0.109 \mathrm{~m}$ & Intercept factor $/ \gamma$ & 0.99 \\
Glass outer diameter $/ d_{\mathrm{co}}$ & $0.115 \mathrm{~m}$ & Emittance of the absorber $/ \varepsilon_{\mathrm{r}}$ & 0.2
\end{tabular}

Table 2 Constants and variables operating conditions for mono and hybrid nanofluid

\begin{tabular}{llll}
\hline Parameter & Symbols & Mono & Hybrid \\
\hline Radiation beam intensity & $G_{\mathrm{b}}$ & $1000 \mathrm{~W} \mathrm{~m}^{-2}$ & $1000 \mathrm{~W} \mathrm{~m}^{-2}$ \\
Surrounding convection & $h_{\text {out }}$ & $10 \mathrm{~W} \mathrm{~m}^{-2} \mathrm{~K}^{-1}$ & $10 \mathrm{~W} \mathrm{~m}^{-2} \mathrm{~K}^{-1}$ \\
Ambient temperature & $T_{\text {am }}$ & $300 \mathrm{~K}$ & $300 \mathrm{~K}$ \\
Sun temperature & $T_{\text {sun }}$ & $5770 \mathrm{~K}$ & $5770 \mathrm{~K} \mathrm{[31]}$ \\
Inlet temperature & $T_{\text {in }}$ & $300 \mathrm{~K}-600 \mathrm{~K}$ & $300 \mathrm{~K}-600 \mathrm{~K}$ \\
Volume flow rate & $V_{\text {flow }}$ & $150 \mathrm{~L} \mathrm{~min}^{-1}$ & $150 \mathrm{~L} \mathrm{~min}$ m $^{-1}$ \\
Nanoparticle volume fraction & $\Phi$ & $4 \%$ & Fraction mix $50: 50$ \\
Mono and HNF (cases) & Base fluid & $\mathrm{Al}_{2} \mathrm{O}_{3}, \mathrm{CeO}_{2}, \mathrm{CuO}$ & $\mathrm{Al}_{2} \mathrm{O}_{3}+\mathrm{CeO}_{2}, \mathrm{Al}_{2} \mathrm{O}_{3}+\mathrm{CuO}$ \\
& Syltherm 800 & & \\
\hline
\end{tabular}
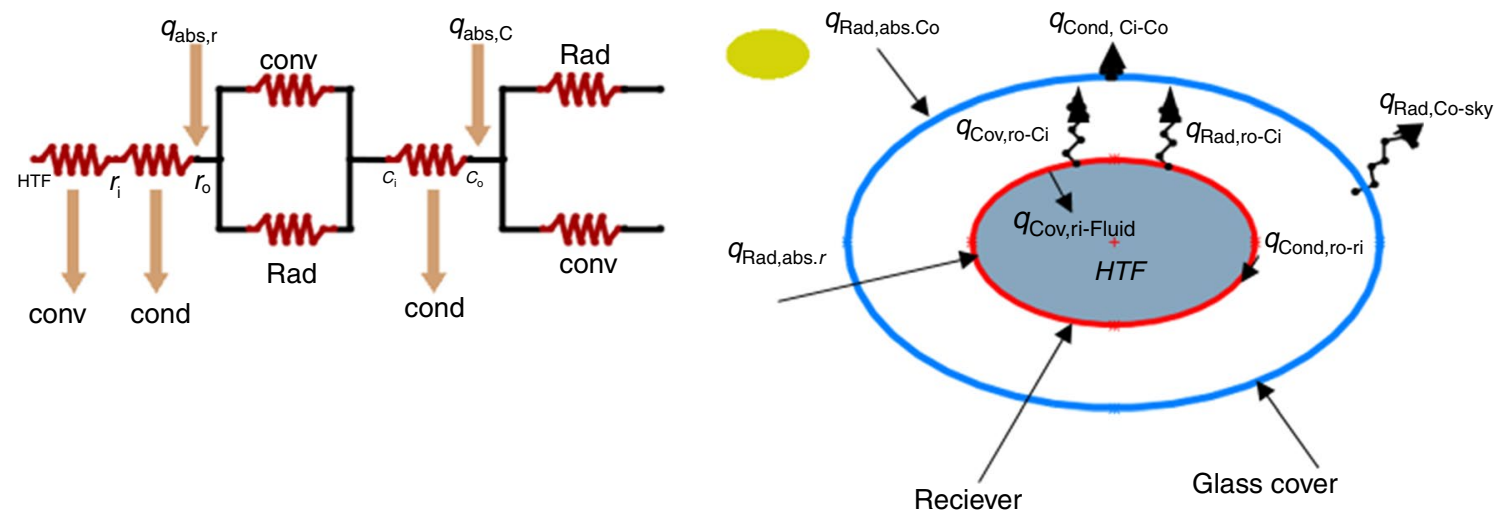

Fig. 2 Evacuated tube receiver heat modes and resistance nods descriptive

balance equations at the different nods. The second point defines the resulted equations of thermal efficiency, heat losses, and various temperatures by collecting different known parameters and dimensions together in five symbols called $\mathrm{K}$, as summarized in Table 3, whereas the following equations described Taylor series assumption and the main equations that used to cover the thermal performance of the PTC [35].

Thermal losses equation by radiation and convection from cover glass to surrounding under negligible contact thermal losses can be expressed as follows:
$Q_{\text {loss }}=A_{\mathrm{co}} \cdot \varepsilon_{\mathrm{c}} \cdot \sigma \cdot\left(T_{\mathrm{co}}^{4}-T_{\mathrm{am}}^{4}\right)+A_{\mathrm{co}} \cdot h_{\mathrm{out}} \cdot\left(T_{\mathrm{co}}-T_{\mathrm{am}}\right)$

The temperature of the cover is assumed to be close to the ambient temperature. According to this, and using the Taylor series, the fourth-order temperatures simplify as shown in Eq. (2), where the validation of this assumption proved it is correct by obtained a small variation between the model results and different previous studies (whatever experimental or numerical results) as shown in Fig. 4: 
Table 3 Symbols and parameter definitions [35]

\begin{tabular}{ll}
\hline Symbols & Definition \\
\hline$K_{1}$ & $A_{\mathrm{co}} \cdot \varepsilon_{\mathrm{c}} \cdot \sigma \cdot 4 \cdot T_{\mathrm{am}}^{3}+A_{\mathrm{co}} \cdot h_{\mathrm{out}}$ \\
$K_{2}$ & $A_{r o} \cdot \varepsilon_{r}^{*} \cdot \sigma \cdot\left[1+\frac{4 \cdot T_{a m}^{3} \cdot A_{r o} \cdot \varepsilon_{r}^{*} \cdot \sigma}{K_{1}}\right]^{-1}$ \\
$K_{3}$ & {$\left[\frac{1}{A_{\mathrm{ri}} \cdot h}+\frac{1}{2 \cdot \dot{m} \cdot c_{\mathrm{p}}}\right]^{-1}$} \\
$K_{4}$ & $\eta_{\mathrm{opt}} \cdot\left[1+\frac{4 \cdot T_{\mathrm{in}}^{3} \cdot K_{2}}{K_{3}}\right]^{-1}$ \\
$K_{5}$ & $K_{2} \cdot\left[1+\frac{4 \cdot T_{\mathrm{in}}^{3} \cdot K_{2}}{K_{3}}\right]^{-1}$ \\
$\varepsilon_{\mathrm{r}}^{*}$ & {$\left[\frac{1}{\varepsilon_{\mathrm{r}}}+\frac{1-\varepsilon_{\mathrm{c}}}{\varepsilon_{\mathrm{c}}} \cdot \frac{A_{\mathrm{ro}}}{A_{\mathrm{ci}}}\right]^{-1}$} \\
\hline
\end{tabular}

$T_{\mathrm{co}}^{4}-T_{\mathrm{am}}^{4} \cong 4 \cdot T_{\mathrm{am}}^{3} \cdot\left(T_{\mathrm{co}}-T_{\mathrm{am}}\right)$

So, in the first node, heat losses were written as shown in Eq. (3), where the main known parameter was put in brackets, covered the first $K$ symbols as summarized in Table 3 .

$Q_{\text {loss }}=\left\{A_{\mathrm{co}} \cdot \varepsilon_{\mathrm{c}} \cdot \sigma \cdot 4 \cdot T_{\mathrm{am}}^{3}+A_{\mathrm{co}} \cdot h_{\mathrm{out}}\right\} \cdot\left(T_{\mathrm{co}}-T_{\mathrm{am}}\right)$

The energy balance in the receiver part was estimated according to Eq. (4) based on the equalization between the summation of the heat loss and useful heat with the multiplication results of the optical efficiency and solar irradiation.

$\eta_{\mathrm{opt}} \cdot Q_{\mathrm{s}}=Q_{\mathrm{u}}+Q_{\text {loss }}$

where the main thermal performance findings and definitions were selected and discussed as follows:

Thermal efficiency for PTC can be estimated as:

$\eta_{\mathrm{th}}=K_{4}-K_{5} \cdot \frac{T_{\mathrm{in}}^{4}-T_{\mathrm{am}}^{4}}{A_{\mathrm{a}} * G_{\mathrm{b}}}$.

Thermal losses $\left(Q_{\text {loss }}\right)$ can be expressed as:

$Q_{\text {loss }}=\left(\eta_{\mathrm{opt}}-K_{4}\right) \cdot Q_{\mathrm{s}}+K_{5} \cdot\left(T_{\mathrm{in}}^{4}-T_{\mathrm{am}}^{4}\right)$

In addition, receiver, cover glass, and outlet temperatures were covered as in the given equations:

$$
\begin{aligned}
& T_{\mathrm{r}}=T_{\mathrm{in}}+\frac{K_{4}}{K_{3}} \cdot Q_{\mathrm{s}}-\frac{K_{5}}{K_{3}} \cdot\left(T_{\mathrm{in}}^{4}-T_{\mathrm{am}}^{4}\right) \\
& T_{\mathrm{c}}=T_{\mathrm{am}}+\frac{\eta_{\mathrm{opt}}-K_{4}}{K_{1}} \cdot Q_{\mathrm{s}}+\frac{K_{5}}{K_{1}} \cdot\left(T_{\mathrm{in}}^{4}-T_{\mathrm{am}}^{4}\right)
\end{aligned}
$$

Finally, the outlet temperature and mean fluid temperature can be found in Eqs. (9 and 10):
$T_{\text {out }}=T_{\text {in }}+\frac{K_{4}}{\dot{m} \cdot C_{\mathrm{p}}} \cdot Q_{\mathrm{s}}-\frac{K_{5}}{\dot{m} \cdot C_{\mathrm{p}}} \cdot\left(T_{\mathrm{in}}^{4}-T_{\mathrm{am}}^{4}\right)$

$T_{\mathrm{fm}}=T_{\mathrm{in}}+\frac{K_{4}}{2 \cdot \dot{m} \cdot C_{\mathrm{p}}} \cdot Q_{\mathrm{s}}-\frac{K_{5}}{2 \cdot \dot{m} \cdot C_{\mathrm{p}}} \cdot\left(T_{\mathrm{in}}^{4}-T_{\mathrm{am}}^{4}\right)$

To achieve previous finding equations, some parameters should be defined and known to present the thermal performance of the PTC. Those parameters that will be represented in the following equations are heat transfer coefficient $(h)$ and various dimensionless numbers like Nusselt $(\mathrm{Nu})$, Reynolds (Re), and Prandtl (Pr). The various parameters were obtained using Eqs. (11-14), where mainly Nusselt number was obtained using Dittus-Boelter equation to cover the turbulent regime flow in our research [35].

$h=\frac{\mathrm{Nu} \cdot k}{d_{\mathrm{ri}}}$

$\mathrm{Nu}=0.023 \cdot \mathrm{Re}^{0.8} \cdot \stackrel{0.4}{\mathrm{Pr}}$

$\operatorname{Re}=\frac{4 \cdot \dot{m}}{\pi \cdot d_{\mathrm{ri}} \cdot \mu}$

$\operatorname{Pr}=\frac{\mu \cdot C_{\mathrm{p}}}{k}$

Evaluation exergy efficiency for different base fluid types, mono nanofluid, and HNF was expressed in Eqs. (15-18). Equation (15) is presented to demonstrate the output exergy [37, 38], while Eq. (16) represents Petela formula that was used to calculate obtainable solar exergy [39]. Finally, Eq. (17) expresses exergetic efficiency, where this parameter aimed to get the ability of the PTC to produce electricity $[38,40]$.

$E_{\mathrm{u}}=Q_{\mathrm{u}}-\dot{m} \cdot C_{\mathrm{p}} \cdot T_{\mathrm{am}} \cdot \ln \left(\frac{T_{\text {out }}}{T_{\mathrm{in}}}\right)$

$E_{\mathrm{s}}=A_{\mathrm{a}} \cdot G_{\mathrm{b}} \cdot\left[1-\frac{4}{3} \cdot\left(\frac{T_{\mathrm{am}}}{T_{\text {sun }}}\right)+\frac{1}{3} \cdot\left(\frac{T_{\mathrm{am}}}{T_{\text {sun }}}\right)^{4}\right]$

$\eta_{\mathrm{ex}}=\frac{E_{\mathrm{u}}}{E_{\mathrm{s}}}$

Moreover, the assessment of the pressure drop also was explained to cover the effect of using hybrid and mono nanoparticle and compare various results together with variable inlet temperature. In this research, the Darcy friction factor obtained using Blasius equation was used to obtain 
the pressure drop trends for various TF as mentioned in Eqs. (18) and (19) for turbulent flow [41].

$f_{\mathrm{r}, \text { the }}=0.079 /\left(R_{\mathrm{e}}\right)^{0.25}$

$\Delta P_{\text {the }}=f_{\mathrm{r} \text { the }} \cdot \frac{L}{d_{\mathrm{ri}}} \cdot\left(\frac{1}{2} \cdot \rho \cdot u^{2}\right)$

\section{Mono and hybrid nanofluids specifications}

This section aimed to define the main equations and correlations that were taken from the literature to predict and define the produced thermal properties of different mono and HNF. Those equations and their main correlations were simplified using different symbols to describe the resulted thermal properties. For this research, a combination of Syltherm 800 as a base fluid that subscribed by (bf) with a mono and hybrid nanoparticles of $\mathrm{Al}_{2} \mathrm{O}_{3}$ nanoparticle subscribed by (np1) and $\mathrm{CeO}_{2}$ nanoparticle or $\mathrm{CuO}$ that subscribed by (np2) was used to define nanofluid whether mono or hybrid nanofluids are subscribed by (hnf) [42]. Thermal efficiency was examined under the effect of using mono nanofluid for

$C_{\mathrm{p}, \mathrm{hnf}}=\frac{\varphi_{\mathrm{np} 1} \cdot \rho_{\mathrm{np} 1} \cdot C_{\mathrm{p}, \mathrm{np} 1}+\varphi_{\mathrm{np} 2} \cdot \rho_{\mathrm{np} 2} \cdot C_{\mathrm{p}, \mathrm{np} 2}+\left(1-\varphi_{\mathrm{tot}}\right) \cdot \rho_{\mathrm{bf}} \cdot C_{\mathrm{p}, \mathrm{bf}}}{\rho_{\mathrm{hnf}}}$ each nanofluid at medium and high inlet temperature levels under volume fraction $(\varphi)$ for any nanoparticle equal $4 \%$ while for the HNF, the calculated results occurred under the same conditions for two different types under total volume fraction ( $\varphi$ tot) equal of $4 \%$. This total volume fraction was divided under mixing fraction 50:50, which means $2 \%$ volume fraction for each nanoparticle. The following equation describes the total volume fraction and how it can define nanofluid properties whatever mono or HNF. Also, Fig. 3 is used to summarize different tested nanoparticles.

The total volume fraction combination resulted by inserting different types of the mentioned cases is shown in Fig. 3 with base fluid expressed, as shown in Eq. (20) [43].

$\varphi_{\mathrm{tot}}=\varphi_{\mathrm{np} 1}+\varphi_{\mathrm{np} 2}$

Nanofluid density $/ \mathrm{kg} \mathrm{m}^{-3}$ expressed in Eq. (21) was mentioned in different research studies [31, 42].

$\rho_{\mathrm{hnf}}=\varphi_{\mathrm{np} 1} \cdot \rho_{\mathrm{np} 1}+\varphi_{\mathrm{np} 2} \cdot \rho_{\mathrm{np} 2}+\left(1-\varphi_{\mathrm{tot}}\right) \cdot \rho_{\mathrm{bf}}$

Specific heat capacity $/ \mathrm{J} \mathrm{kg}^{-1} \mathrm{~K}^{-1}$ formula in Eq. (22) is used to cover the mono and HNF. This formula has been used widely in the literature because of its ability to cover a wide range of the volume concentration besides its uses in different nanofluid types [42].
Fig. 3 Examined mono and hybrid nanofluids cases

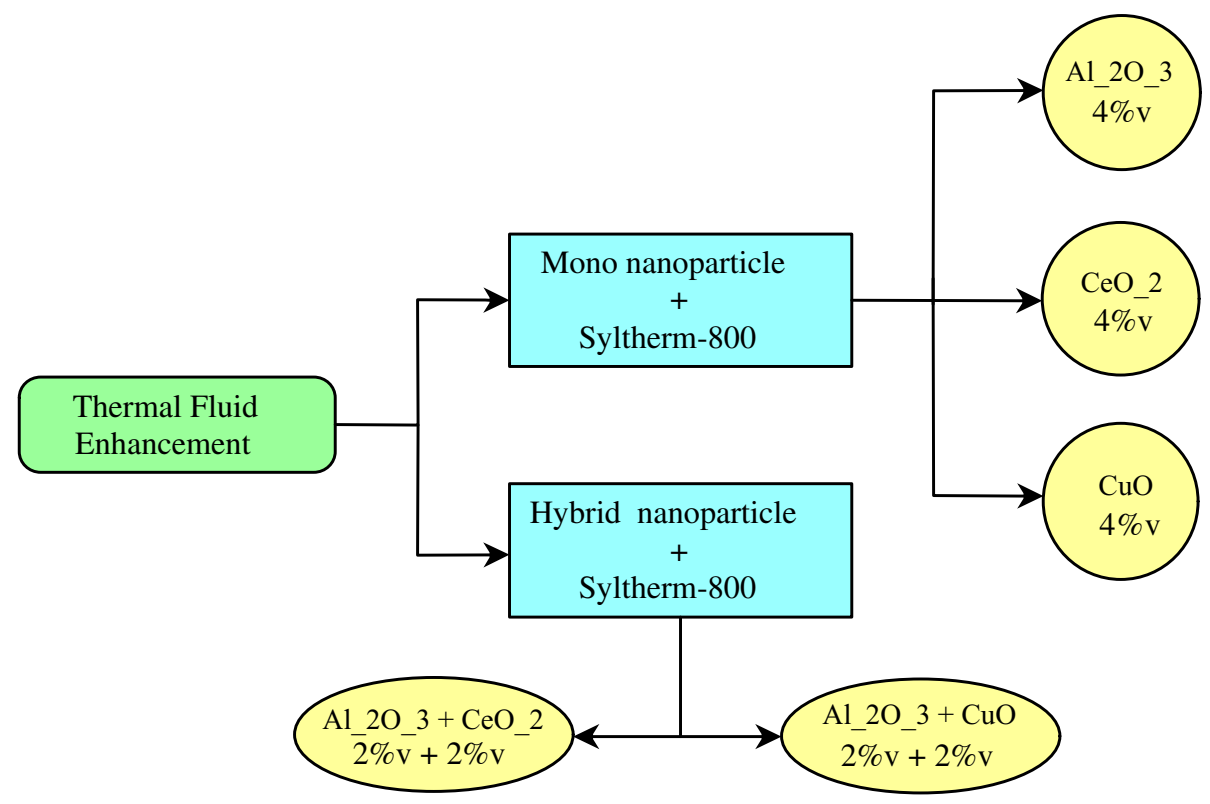


whereas the thermal conductivity of the nanofluids was obtained using Maxwell correlation, which was extended to cover hybrid and mono nanofluids as represented in Eq. (23) $[42,44]$. regarding its ability to predict a reasonable result, and the nonexistence of special correlations to cover oil under high temperature range. Finally, the examined used nanoparticles' thermal properties through this research were obtained from

$k_{\mathrm{hnf}}=k_{\mathrm{bf}}\left[\frac{\frac{\varphi_{\mathrm{np} 1} \cdot k_{\mathrm{np} 1}+\varphi_{\mathrm{np} 2} \cdot k_{\mathrm{np} 2}}{\varphi_{\mathrm{tot}}}+2 \cdot k_{\mathrm{bf}}+2 \cdot\left(\varphi_{\mathrm{np} 1} \cdot k_{\mathrm{np} 1}+\varphi_{\mathrm{np} 2} \cdot k_{\mathrm{np} 2}\right)-2 \cdot \varphi_{\mathrm{tot}} \cdot k_{\mathrm{bf}}}{\frac{\varphi_{\mathrm{np} 1} \cdot k_{\mathrm{np} 1}+\varphi_{\mathrm{np} 2} \cdot k_{\mathrm{np} 2}}{\varphi_{\mathrm{tot}}}+2 \cdot k_{\mathrm{bf}}-2 \cdot\left(\varphi_{\mathrm{np} 1} \cdot k_{\mathrm{np} 1}+\varphi_{\mathrm{np} 2} \cdot k_{\mathrm{np} 2}\right)+\varphi_{\mathrm{tot}} \cdot k_{\mathrm{bf}}}\right]$

Lastly, Brinkman model correlation was used to obtain dynamic viscosity of the nanofluid as presented in Eq. (24) [45].

$\mu_{\mathrm{hnf}}=\mu_{\mathrm{bf}} \frac{1}{(1-\varphi)^{2.5}}$

Mainly, for the base fluid the correlations that were used to cover the thermal properties of Syltherm 800 itself were picked from the literature as mentioned by Mwesigye and Huan [46] research. The derived polynomial expirations for different thermal properties with variable temperatures presented in their research were used in our research as shown in the following equations [46].

$C_{\mathrm{pbf}}=1.10787+1.70736 .10^{-3} T$

$\rho_{\mathrm{bf}}=1.291 .10^{-3}-1.52115 T+1.79133 .10^{-3} T^{2}-1.671545 T^{3}$

$k_{\mathrm{bf}}=1.9013 \cdot 10^{-1}-1.88053 \cdot 10^{-4} T$.

Dynamic viscosity properties that were divided into two regression polynomials depend on the inlet temperature as represented in Eq. (28) for $233.15 \leq T \leq 343 \mathrm{~K}$ and Eq. (29) for $343 \leq T \leq 673.15 \mathrm{~K}$.

$$
\begin{aligned}
\mu_{\mathrm{bf}}= & 5.14 .10^{4}-9.6165 .10^{2} T+7.502 T^{2}-3.1246 .10^{-2} T^{3} \\
& +7.322 .10^{-5} T^{4}-9.1463 .10^{-8} T^{5}+4.7562 .10^{-11} T^{6}
\end{aligned}
$$

$\mu_{\mathrm{bf}}=9.8856 .10-7.309 .10^{-1} T+2.21917 .10^{-3} T^{2}$

$$
-3.42377 .10^{-6} T^{3}+2.6683 .10^{-9} T^{4}
$$

According to the comparison of the effect of using different mentioned nanofluids in our research, previous general correlations that mentioned in this section were used to define the thermal properties of those modified fluids, the literature as shown in Table $4[32,34]$.

In this research, Nusselt number is considered as one of the most effective factors that must be defined, whatever for the base fluid, mono nanofluid, and HNF to predict the heat transfer coefficient of the fluid so that Minea correlation as represented in Eq. (30) was used to cover Nusselt number for the HNF; this referred to its ability to cover different types of hybrid nanofluids containing aluminum oxide as a part of the combination. Also, this correlation was validated for the turbulent flow regime and for the total volume fraction 3-4\% as in our work. So, this equation was used to obtain Nusselt number for the hybrid combination through this work [47].

$\mathrm{Nu}=0.0074 \cdot \operatorname{Re}^{0.9} \cdot \operatorname{Pr}^{0.67} \cdot \varphi^{0.063}$

The Nusselt number for mono nanofluid was obtained using Pak and Cho correlation to cover the resulted value of different monotypes. Hence, this equation has been proved its validity for variable types of nanoparticle under turbulent regime. Equation (31) is used to obtain Nusselt number for the mono nanofluids of this research [48].

$\mathrm{Nu}=0.021 \cdot \operatorname{Re}^{0.8} \cdot \operatorname{Pr}^{0.5}$

\section{Results and discussion}

\section{Thermal model validation}

Validation of the thermal efficiency results was done and compared for the same PTC model using different TFs. The first validation occurred using base fluid "Syltherm 800 " under various operating conditions as conducted by Dudley experimental reports [36]. The thermal efficiency results showed high accuracy behavior with the experimental results of the Sandia National Laboratories (SNL), as illustrated in Fig. 4 with a mean deviation of $1.15 \%$. This value
Table 4 Nanoparticles thermal properties

\begin{tabular}{lccc}
\hline Property/nanoparticles & $\begin{array}{l}\text { Aluminum oxide } \\
\text { nanoparticle } \mathrm{Al}_{2} \mathrm{O}_{3}\end{array}$ & $\begin{array}{l}\text { Cerium oxide nano- } \\
\text { particle } \mathrm{CeO}_{2}\end{array}$ & $\begin{array}{l}\text { Copper oxide nano- } \\
\text { particle } \mathrm{CuO}\end{array}$ \\
\hline Specific heat $\mathrm{C}_{\mathrm{pnp}} / \mathrm{J} \mathrm{kg}^{-1} \mathrm{~K}^{-1}$ & 765 & 460 & 551 \\
Density $\rho_{\mathrm{np}} / \mathrm{kg} \mathrm{m}^{-3}$ & 3970 & 7220 & 6000 \\
Thermal conductivity k & 12 & 33 \\
\hline
\end{tabular}




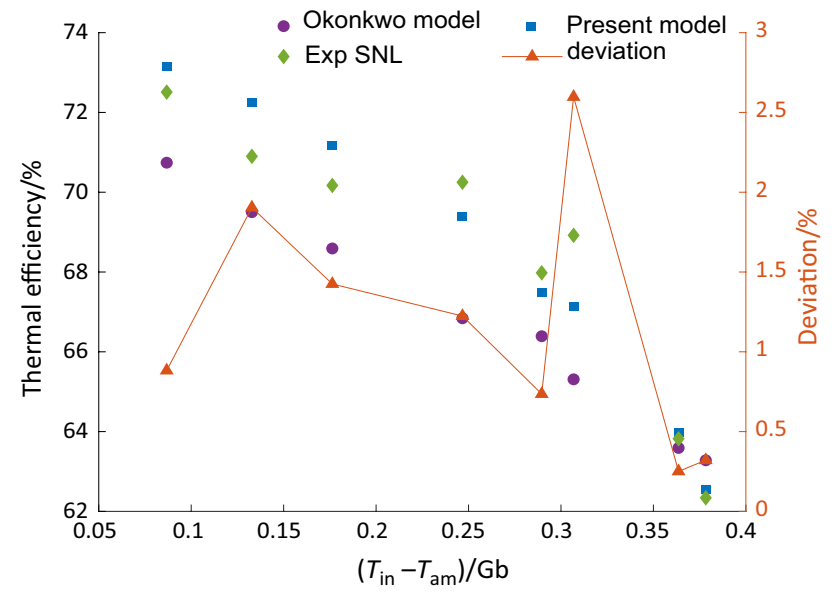

Fig. 4 Validation present model with literature experimental and numerical results $[36,49]$

is acceptable and reliable in PTC application [36]. Moreover, the present model was compared with other numerical work to prove the accuracy; the results of thermal efficiency of the present model showed more precise results and lower mean deviation results compared with Okonkwo work [49], which has a mean deviation equal $2.5 \%$ with same experimental results.

The second validation occurred using mono and HNF which consists of alumina and titanium oxide inserting in Syltherm 800 under volume fraction equal 3\% as investigated by Bellos and Tzivanidis [31]. The obtained results of the present model were illustrated as shown in Fig. 5. The results showed high accuracy behavior [31].

\section{Thermal performance enhancement}

In this research, there were some parameters taken as constants because this research aimed to compare different mono and HNF together in the same article so that the radiation intensity and ambient temperature were taken $1000 \mathrm{~W} \mathrm{~m}^{-2}$ and $300 \mathrm{~K}$, respectively. Optimum volumetric flow rate used in this research was estimated as shown in Fig. 6. This figure was used to present the outlined results between the efficiency and volumetric flow rate for different inlet temperatures to reach the optimum value. The results showed clear increase in the thermal efficiency when volumetric flow rate increases until it reaches $150 \mathrm{~L} \mathrm{~min}^{-1}$, according to the

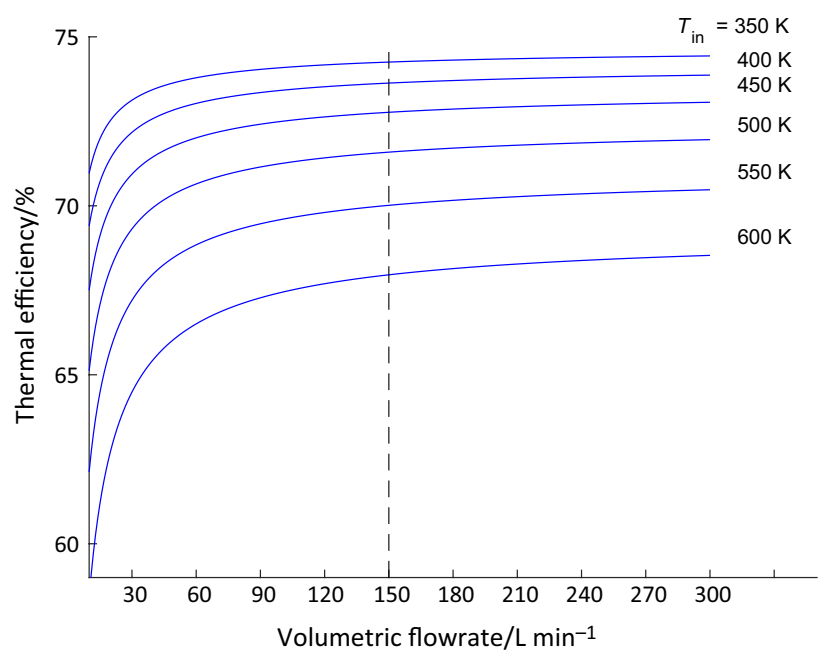

Fig. 6 Effect of change volumetric flow rate on the base fluid thermal efficiency at different inlet temperatures
Fig. 5 Validation model using mono and hybrid nanofluids [31]

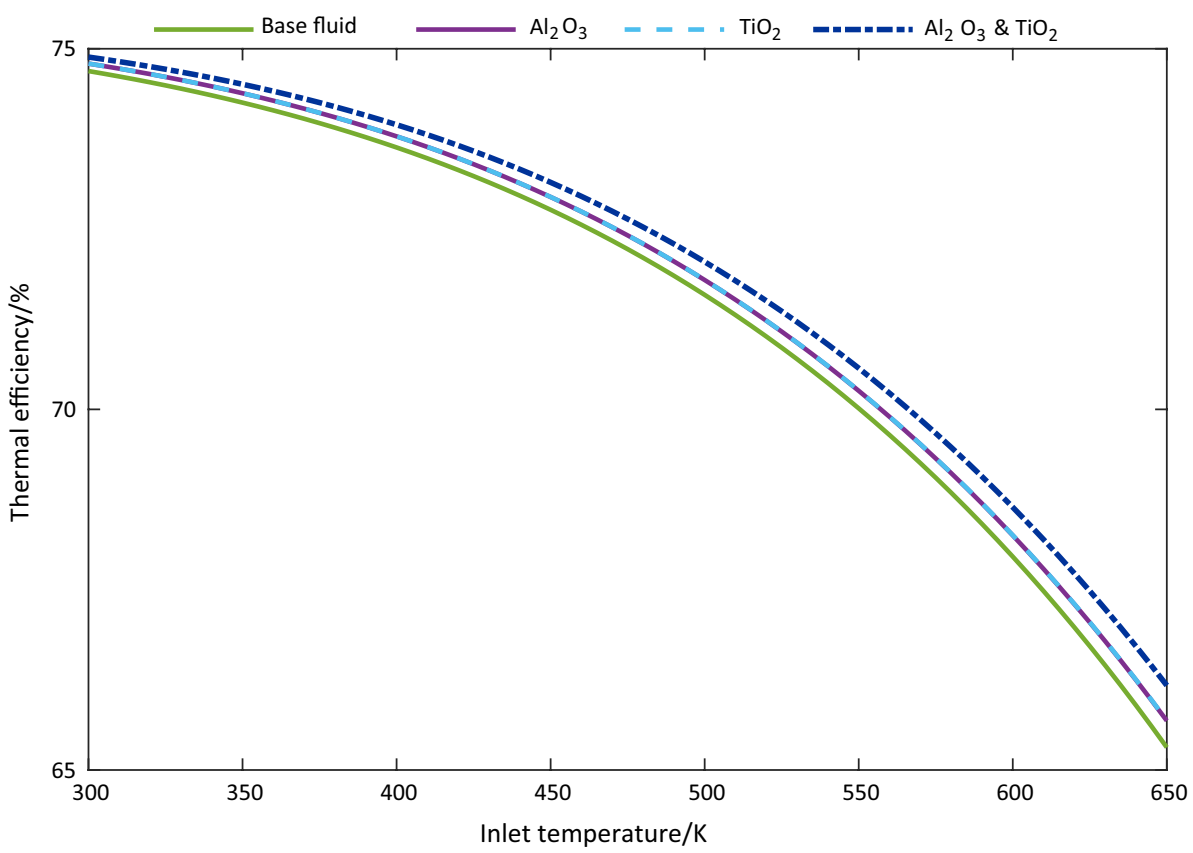


increase in Reynolds number. And it showed a decrease in the thermal efficiency when the temperatures increase, regarding increasing heat losses between absorber and cover. According to this Fig. 6, $150 \mathrm{~L} \mathrm{~min}^{-1}$ was taken as a constant parameter due to this research according to the slight thermal efficiency that occurred when increasing the volumetric flow rate more than this value. So any increase in the pump power will not effect the thermal efficiency [23].

Figure 7a-d contains a description of thermal conductivity, density, specific heat capacity, and dynamic viscosity versus variable inlet temperatures between 300 and $600 \mathrm{~K}$ for all mono and HNF types compared with the base fluid. The main behavior of the results was summarized in the following statements: Thermal conductivity, viscosity, and density were presented enhancement in their behavior compared with Syltherm 800, while on the other hand, the specific heat capacity presented an opposite trend compared with base fluid. Moreover, the change in behavior between different types showed variation as follows: Clear enhancement of the thermal conductivity occurred compared with base fluid, but with a slight variation between nanofluids. This enhancement in the thermal conductivity can be referred to use Maxwell correlation Eq. (23) which estimates thermal conductivity. Moreover, Eq. (23) is based only on the concentration without any consideration of the temperature and nanoparticles specifications [50]. Despite this small effect, it has an efficient effect on the thermal performance of the PTC, as was shown in this work. On the other hand, the effect of using several nanofluids was clearly in density and specific heat capacity behavior between nanofluid types besides base fluid. Finally, the viscosity that illustrated in Fig. 7d showed increase in the viscosity effect for all nanofluids compared with the base fluid, but it did not show any variation in the dynamic viscosity behavior between different nanofluid types according to the used Brinkman model in Eq. (19) that is based on the base fluid viscosity and total

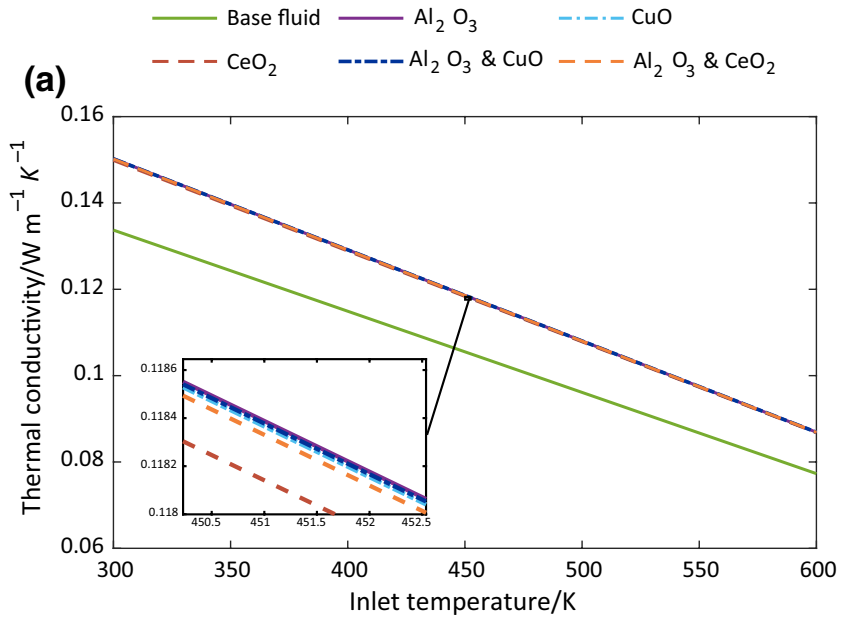

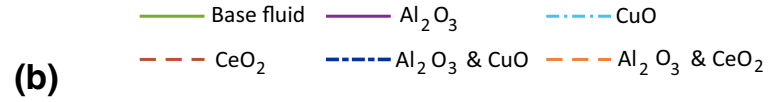
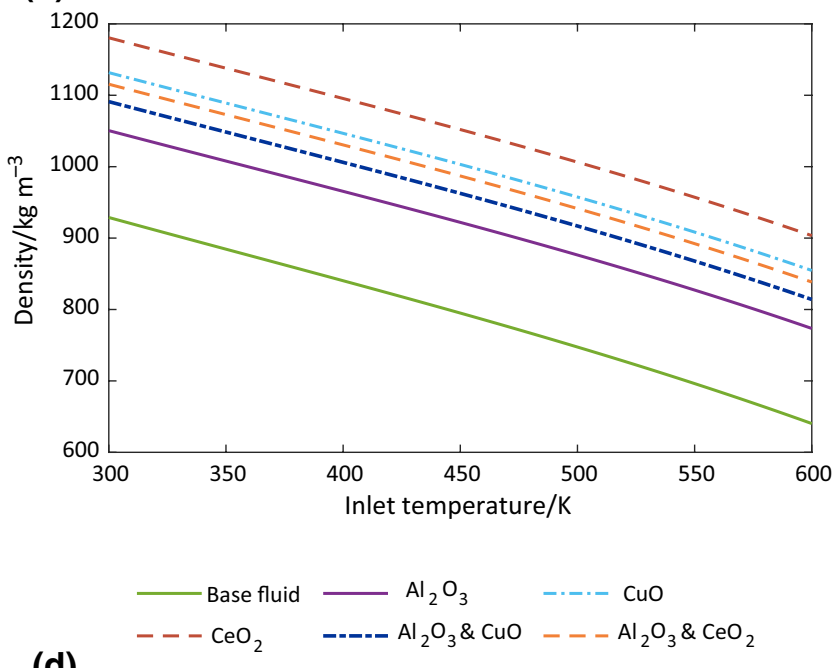

(d)

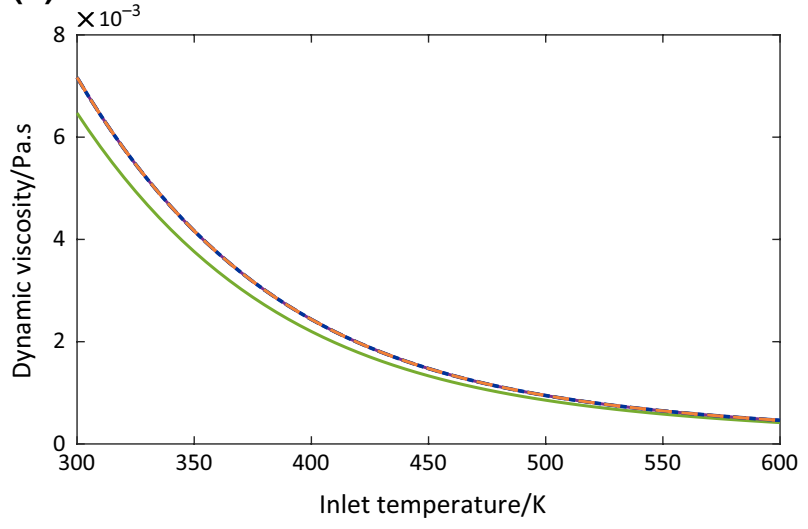

Fig. 7 Thermal properties of the base and various nanofluids at different temperatures and flow rate equal to $150 \mathrm{~L} \mathrm{~min}^{-1} \mathbf{a}$ thermal conductivity, b density, c specific heat, $\mathbf{d}$ dynamic viscosity 
volume fraction without any consideration of the nanoparticles types [45]. HNFs trends for various properties located in the middle between different mono nanofluids except for the viscosity all of nanofluids have the same trend. For more details about different $\mathrm{HNFs}$, the density of $\mathrm{Al}_{2} \mathrm{O}_{3}$ and $\mathrm{CeO}_{2}$ is higher than that for $\mathrm{Al}_{2} \mathrm{O}_{3}$ and $\mathrm{CuO}$. On the other hand, it has a lower trend in specific heat capacity, while the thermal conductivity seems the same.

Variation effects of the thermal properties for the examined TFs leaded to the enhancement on the thermal performance of the PTC. Figures 8-12 depict Nusselt number, heat transfer coefficient, pressure drop, thermal efficiency, and exergy efficiency altitude for the mentioned nanofluids as well as base fluid versus variable temperature. In addition, Figs. 13-16 present the enhancement phenomena results in accordance with variation clearly understood for different nanofluids. Specifically, Fig. 8 illustrates the mono and hybrid nanofluids impact in the dimensionless Nusselt number compared with base fluid. The results showed an increase in Nusselt number with increasing temperature for various TFs and supported a positive effect reached by using various nanofluids types compared with base fluid. For more details, mono nanofluid of $\mathrm{CeO}_{2}$ reached maximum Nusselt number up to 584.4 compared with $\mathrm{CuO}$ up to 574.3 and $\mathrm{Al}_{2} \mathrm{O}_{3}$ up to 555.2 at a temperature equal to $600 \mathrm{~K}$ and volume fraction $4 \%$. A clear variation occurred between any mono nanofluids and any HNFs, where the results presented slight variation between the same types; this referred to the Nusselt number definition in Eqs. $(25,26)$ and thermal properties of the various types. So, maximum Nusselt numbers for $\mathrm{HNF}$ occurred using $\mathrm{Al}_{2} \mathrm{O}_{3}-\mathrm{CeO}_{2} \mathrm{HNF}$ and reached 996 compared with $\mathrm{Al}_{2} \mathrm{O}_{3}-\mathrm{CuO}$ HNF which increased up to 988.9; these results referred to the increase in the rate of enhancement that occurred in the thermal conductivity and in the density of the $\mathrm{Al}_{2} \mathrm{O}_{3}-\mathrm{CeO}_{2} \mathrm{HNF}$. To clarify this increase,

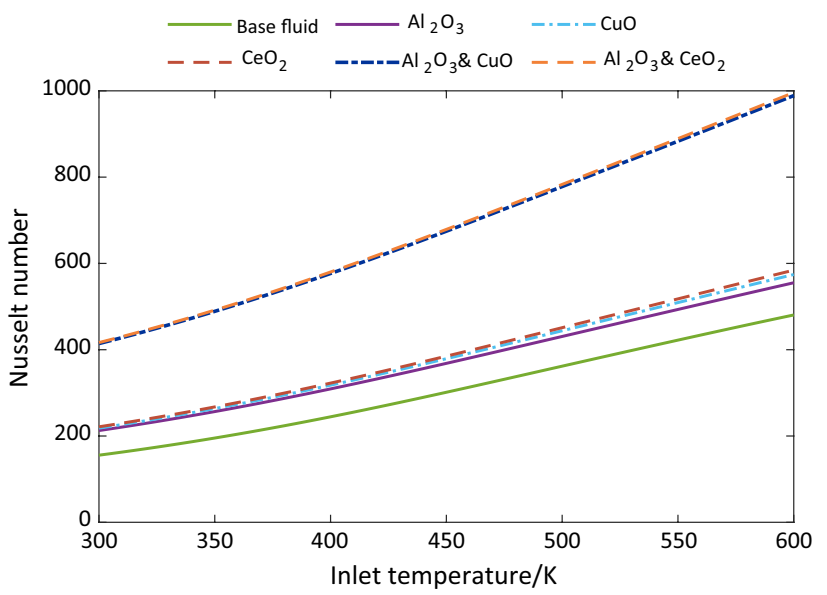

Fig. 8 Nusselt number of the base and various nanofluids at different temperatures and flow rate equal to $150 \mathrm{~L} \mathrm{~min}^{-1}$
Fig. 13 presents enhancement results occurred in Nusselt number for different nanofluids compared with base fluid under the temperature varied from 300 up to $600 \mathrm{~K}$. Major results showed maximum enhancement up to $167.8 \%$ using $\mathrm{Al}_{2} \mathrm{O}_{3}-\mathrm{CeO}_{2} \mathrm{HNF}$ compared with other nanofluids, where the maximum mono nanofluids enhancement occurred using $\mathrm{CeO}_{2}$ up to $42.29 \%$.

The convective heat transfer coefficient considers as a significant factor that has a high impact on the thermal and exergy efficiency of the PTC. Figure 9 shows a higher increase compared with the previous figure for the Nusselt number; this was attributed to the enhancement results of the thermal conductivity which has a high effect in the basic definition of the heat transfer coefficient Eq. (11). Moreover, Fig. 9 demonstrates that the maximum heat transfer coefficient obtained from the same HNF has a high Nusselt number which is alumina cerium oxide combination, whereas the maximum value reached $1316 \mathrm{~W} \mathrm{~m}^{-2} \mathrm{~K}^{-1}$ with a mean value equals $1187 \mathrm{~W} \mathrm{~m}^{-2} \mathrm{~K}^{-1}$ compared with other TF. Also, Fig. 14 depicts enhancement effect of various nanofluids where the maximum enhancement $200.7 \%$ occurred using $\mathrm{HNF}$ of $\mathrm{Al}_{2} \mathrm{O}_{3}-\mathrm{CeO}_{2}$ under total volume concentration equal $4 \%$, where the maximum convection coefficient enhancement for other nanofluids set from the highest to lowest was as follows: $199.2 \%$ for $\mathrm{Al}_{2} \mathrm{O}_{3}-\mathrm{CuO}, 59.47 \%$ for $\mathrm{CeO}_{2}, 57.62 \%$ for $\mathrm{CuO}, 50.63 \%$ for $\mathrm{Al}_{2} \mathrm{O}_{3}$. The resulted enhancement in the dimensionless Nusselt, convection coefficient, and the variation effect of using various types in the resulted pressure drop was the main reasons which leads amelioration in the thermal efficiency performance of the PTC as shown in Fig. 11 so that Fig. 10 displays pressure drop trends of various TF, the significant and variable effect between various hybrid and mono nanofluids types versus the base fluid itself were clear and linked basically to the change in density of various types. As presented in Fig. 7b,

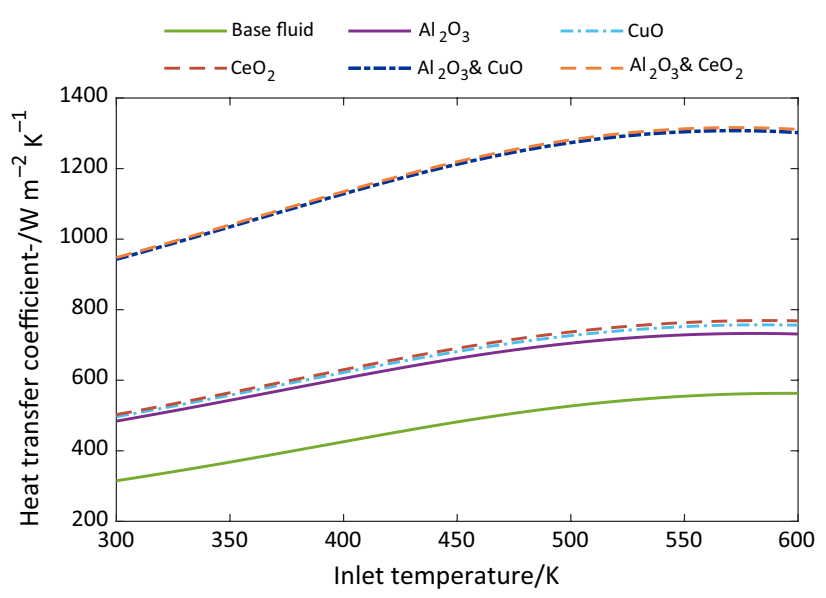

Fig. 9 Heat transfer coefficient of the base and various nanofluids at different temperatures and flow rate equal to $150 \mathrm{~L} \mathrm{~min}^{-1}$ 


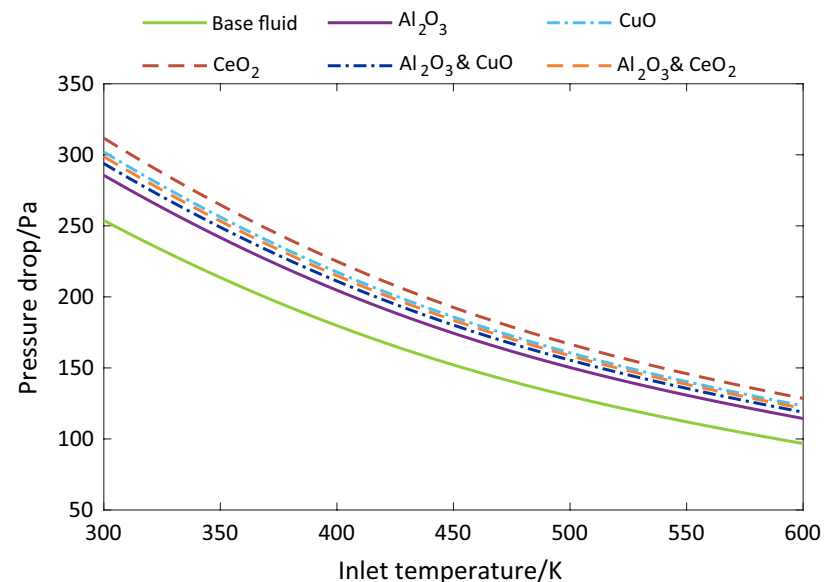

Fig. 10 Pressure drop for the base and various nanofluids at different temperatures and flow rate equal to $150 \mathrm{~L} \mathrm{~min}^{-1}$

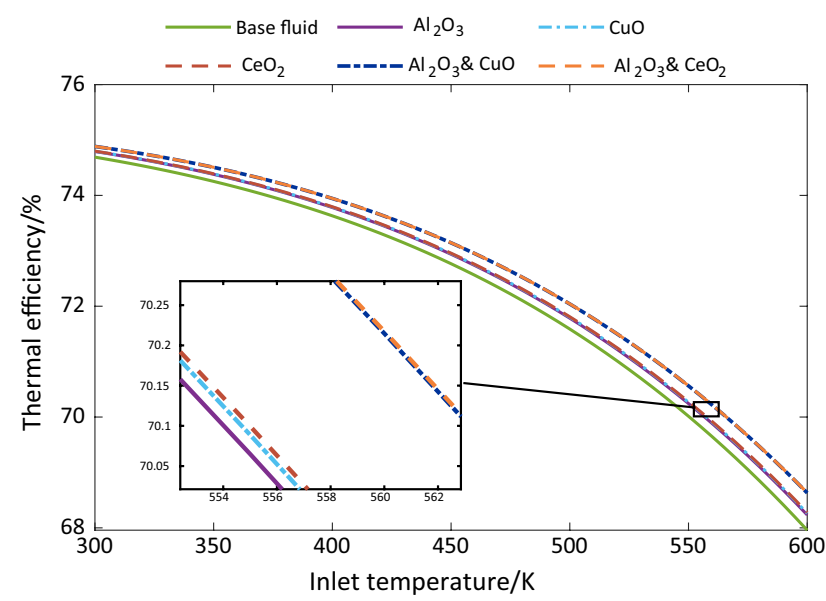

Fig. 11 Thermal efficiency for the base and various nanofluids at different temperatures and flow rate equal to $150 \mathrm{~L} \mathrm{~min}^{-1}$

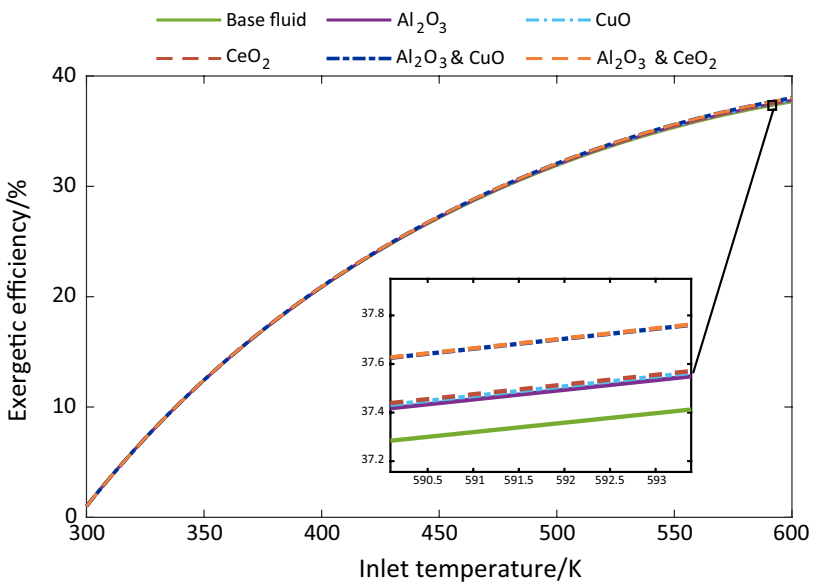

Fig. 12 Exergetic efficiency for the base and various nanofluids at different temperatures and flow rate equal to $150 \mathrm{~L} \mathrm{~min}^{-1}$

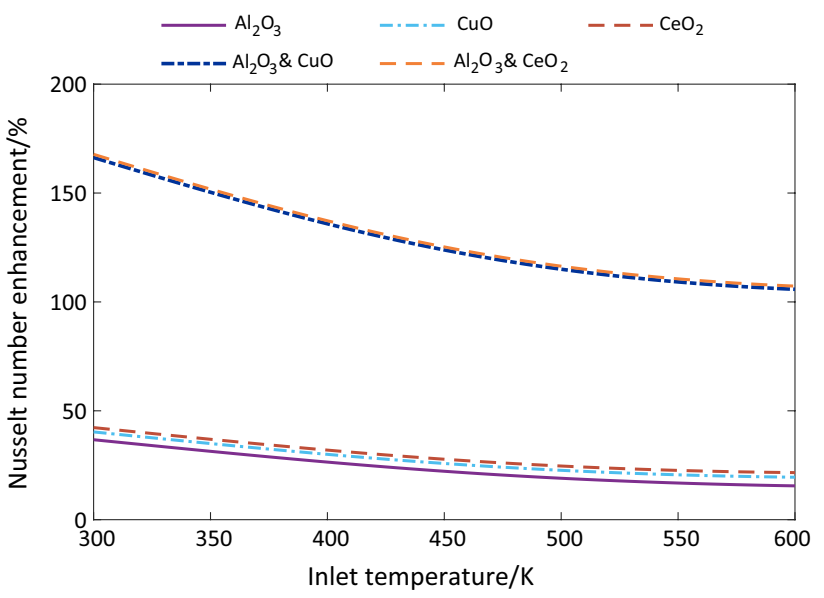

Fig. 13 Nusselt number enhancement for various nanofluids at different temperatures and flow rate equal to $150 \mathrm{~L} \mathrm{~min}^{-1}$

$\mathrm{CeO}_{2}$ mono nanofluid has high density so it has a significant increase in pressure drop compared with other fluids, while the main positive effect of using HNFs was clear in producing lower pressure drop compared with mono ones; this referred to the change occurred in density. This positive effect of using HNFs can help the coming researchers to take this point in their consideration to get high thermal and exergy efficiency with low pumping power. Besides, the pressure drop decreased with increasing temperatures, which was clear and linked to the dynamic viscosity decrease at high inlet temperature; as illustrated in Fig. 7d. Figure 11 exhibits the thermal efficiency results for various TF versus variable inlet temperature; mainly, the results showed a decrease in the thermal efficiency with increasing inlet temperature. This was attributed to increasing receiver temperature that leads to an increase in the heat losses. In addition, the variation of the thermal efficiency between various TF showed unclear trends between different types particularly at low inlet temperature compared with the variation at high inlet temperature. This result was justified according to the highest convective heat transfer coefficient and Nusselt number that were resulted using nanofluid. Besides heat loses at high temperatures, those reasons justify the margin thermal efficiency augmentation at high temperatures. In general, the variation between different nanofluid did not have a high difference particularly between the same group whatever hybrid or mono nanofluid is used. So, the focusing on the thermal efficiency (Fig. 11) was used to present this variation between results, this figure showed that the cerium oxide has the highest thermal efficiency among the other nanoparticles utilized in mono nanofluids, and it has the highest thermal efficiency among HNFs, too. Thermal efficiency enhancement between various nanofluids is presented in Fig. 15 which was used to obtain enhancement results; this figure showed maximum enhancement 1.09\% 


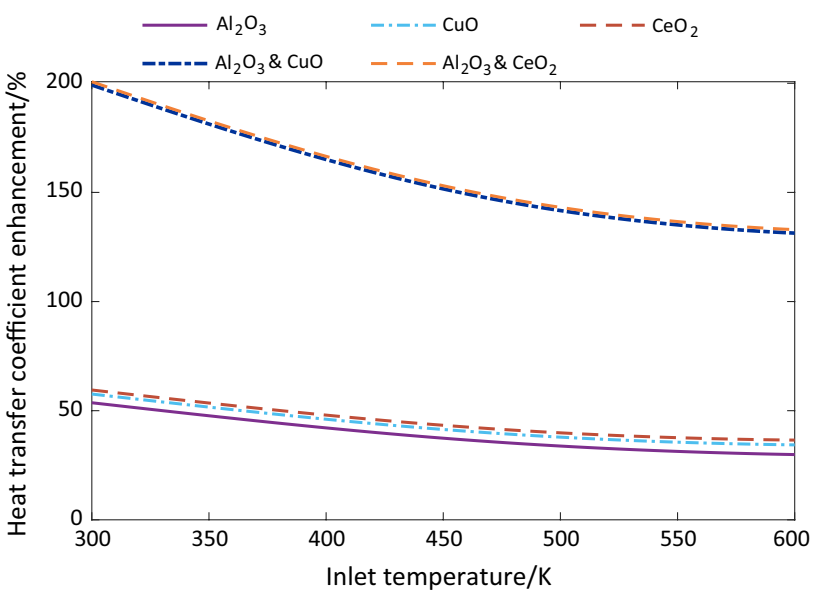

Fig. 14 Heat transfer coefficient enhancement for various nanofluids at different temperatures and flow rate equal to $150 \mathrm{~L} \mathrm{~min}^{-1}$

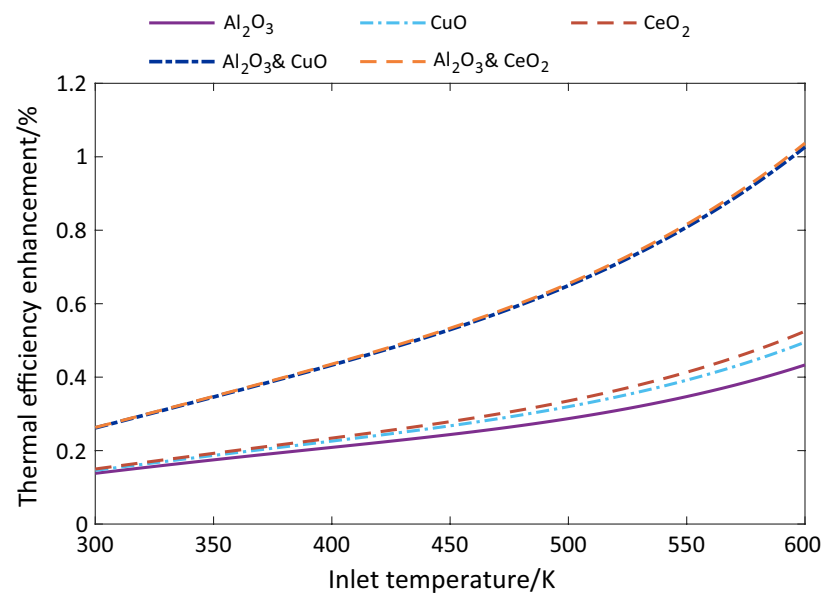

Fig. 15 Thermal efficiency enhancement for the base and various nanofluids at different temperatures and flow rate equal to $150 \mathrm{~L}$ $\min ^{-1}$

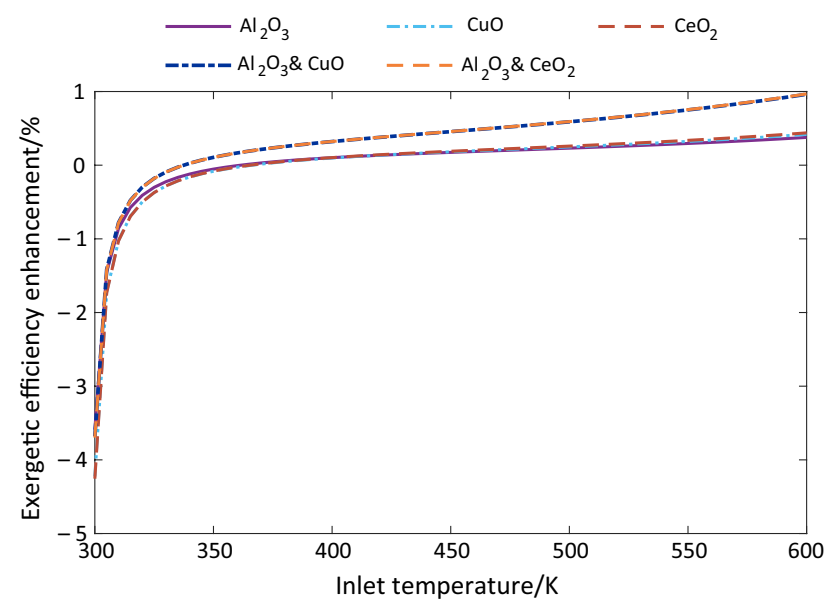

Fig. 16 Exergetic efficiency for the base fluid and various nanofluids at different temperatures and flow rate equal to $150 \mathrm{~L} \mathrm{~min}^{-1}$ using $\mathrm{HNF}$ of $\mathrm{CeO}_{2} / \mathrm{Al}_{2} \mathrm{O}_{3}$ and $0.4705 \%$ when using mono nanofluid of ceria oxide. According to these results, it was obvious that the variation between hybrid and mono nanofluid was clear especially at high inlet temperature, regarding increase in Nusselt number and convective heat transfer results as proven before. And the main definitions of Nusselt number are given in Eq. $(25,26)$.

Finally, assessment exergy efficiency and their enhancement results are presented in Figs. 12, 16, respectively. Figure 12 presents exergy efficiency results and shows gradual increase when the inlet temperature increases for various TF and reached maximum exergy efficiency at high temperatures, and this referred to the increase occurred in inlet temperature coinciding with the reduction in the thermal efficiency [31]. Moreover, exergy efficiency behavior is the same with a little variation at a high inlet temperature of more than $550 \mathrm{~K}$. So, focusing Fig. 12 at high inlet temperature showed the variation effect between various nanofluids with a positive impact for the thermal fluid use any HNFs under a small variance between them. Specifically, maximum exergy efficiency was obtained at high inlet temperature as follows: HNFs get the highest value using cerium alumina oxide and reached $37.12 \%$, while it reached $36.91 \%$ and $36.74 \%$ for mono nanofluids of cerium oxide and base fluid, respectively. Those results reflected in the enhancement attitude, as illustrated in Fig. 16. It shows slight enhancement at high inlet temperatures by using various HNFs, while the maximum enhancement is obtained by using Cerium alumina oxide HNF, which reaches $1.03 \%$. Moreover, Fig. 16 shows a negative attitude in results for all the examined nanofluid for the temperature below $366 \mathrm{~K}$; this is because of the high exergy efficiency that obtained by base fluid compared with other modified fluid below this temperature. This negative sign of the enhancement was justified by Bellos and Tzivanidis [31]. Connecting the relationships between thermal efficiency enhancement and temperature ratio between outlet and inlet as presented in Eq. (15) stated that at low inlet temperature low thermal efficiency enhancement occurred leads to increase in outlet temperature to compensate the decrease in specific heat of the nanofluid, which mean increasing the temperature ratio between outlet and inlet temperatures for all nanofluids. According to that, this increase leads to an increase in the second term of Eq. (15). So, combining this relation with the thermal efficiency enhancement leads directly to explain the results of decreased exergy efficiency of nanofluids below base fluid at low temperatures and why it is enhanced at high inlet temperature [31] where these results were supported by the main aim of using PTC under medium and high temperatures 


\section{Optimum thermal performance description}

Thermal performance and main variation of the thermal properties at the temperature equal to $575 \mathrm{~K}$ were discussed in this section. The temperature has been taken according to Fig. 9 that showed a decrease in the heat transfer coefficient after this temperature because of the decrease in the thermal conductivity rate of the $\mathrm{TF}$ at high inlet temperature as illustrated in Fig. 7a. Surface simulation of the energy and exergy efficiency for the highest thermal performance HNF is expressed in Fig. 17a, b, respectively, which proves clearly the improvement that occurred using hybrid combination whatever in the exergy or energy efficiency compared with mono nanofluids. Aforementioned results were considered as an important points that need focusing in the future to decrease the cost of using nanoparticle, not only by mixing highly price nanoparticle with other nanoparticle types of low price, but also by decreasing the pumping power needs according to the results of the pressure drop of using HNF as pre-described in Fig. 10.

Fig. 18 illustrates the enhancement effect of using various nanofluids at the selected temperature $575 \mathrm{~K}$ and total concentration $4 \%$. Figure 18a presents the thermal and exergy efficiency enhancement for various nanofluids, while Fig. 18b presents Nusselt number and heat transfer coefficient amelioration at the same conditions. The illustrated figures showed a clear variance between mono and hybrid nanofluid especially in the Nusselt number and heat transfer coefficient compared whit the enhancement results in the thermal and exergy efficiency. However, the enhancement figures showed that the hybrid fluid of alumina cerium oxide is the best compared with another nanofluid, whereas the
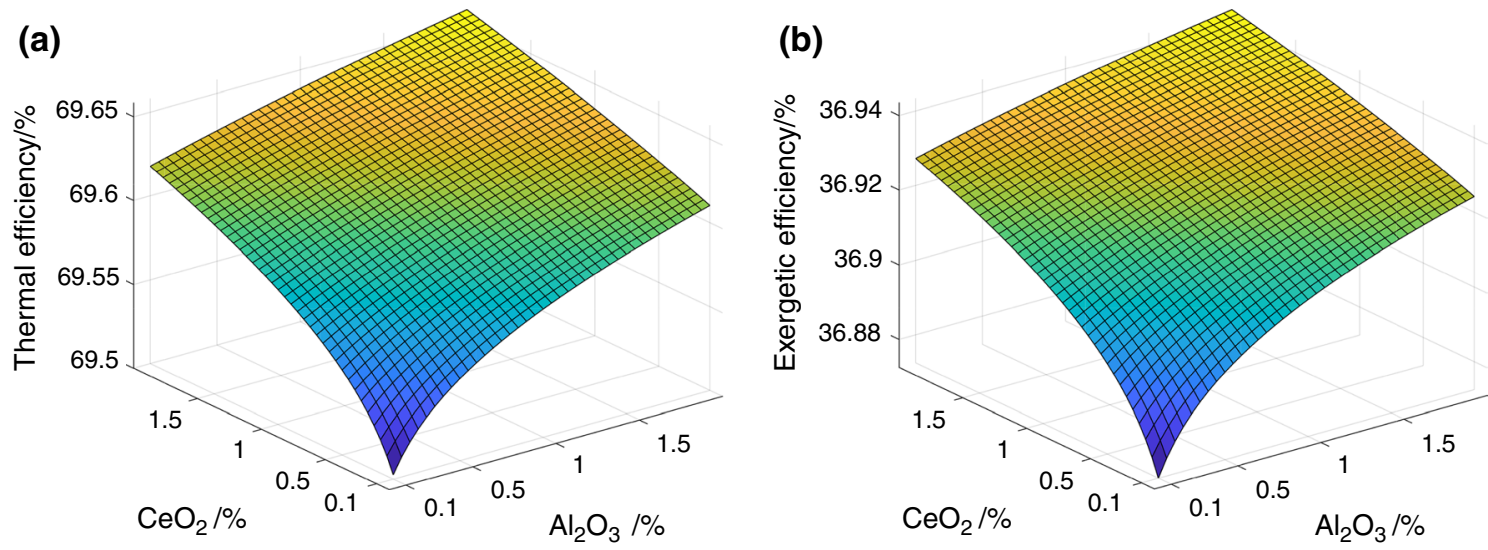

Fig. 17 Surface simulation $\mathrm{Al}_{2} \mathrm{O}_{3}-\mathrm{CeO}_{2}$ at temperature $575 \mathrm{~K}$ a thermal efficiency and $\mathbf{b}$ exergy efficiency

Fig. 18 Enhancement of a thermal efficiency and exergetic efficiency, and $\mathbf{b}$ heat transfer coefficient and Nusselt number for various nanofluids at inlet temperature equal to $575 \mathrm{~K}$ and total concentration $4 \%$
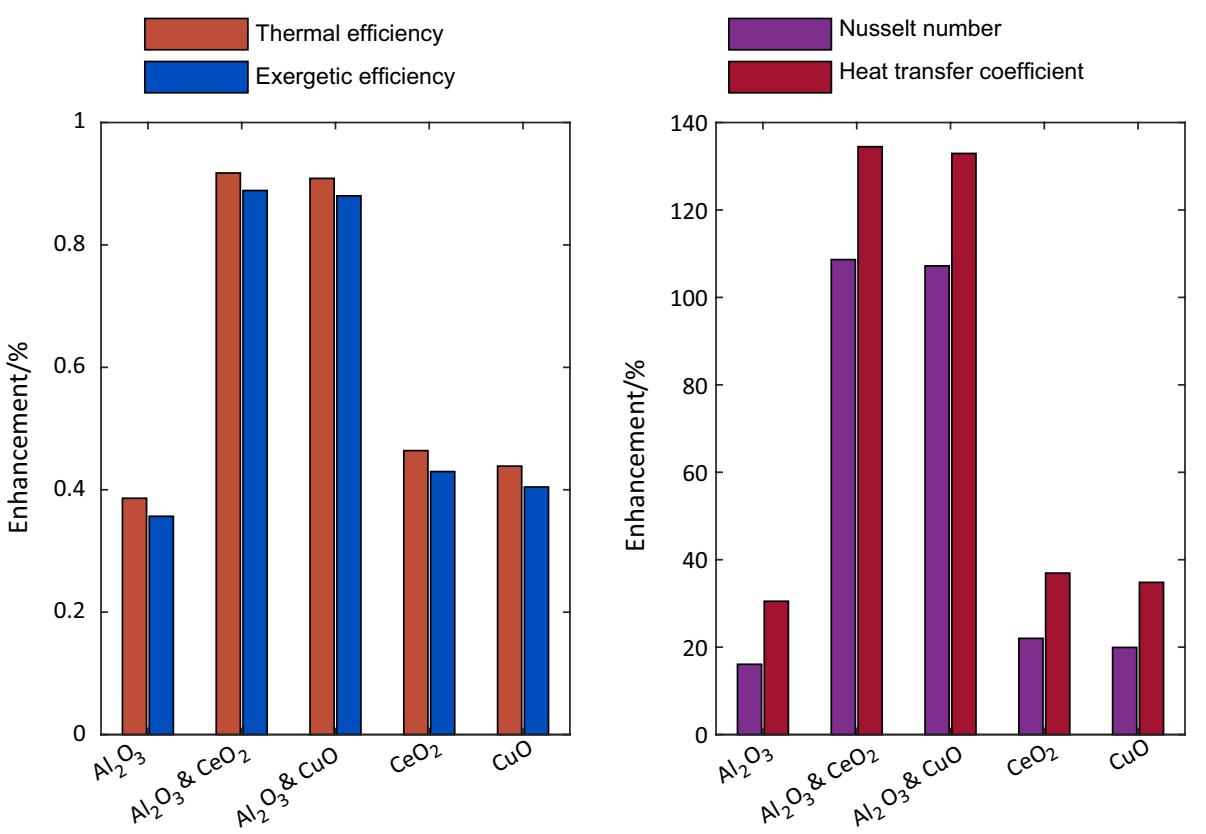
enhancement reached $0.961 \%, 0.9 \%, 135.5 \%, 108.6 \%$ for the thermal efficiency, exergy, heat transfer coefficient, and Nusselt number, respectively.

\section{Optimum thermal properties variation}

This section aimed to predict the nanoparticle thermal properties that efficiently fit with base fluid thermal properties to produce the best efficiency enhancement. This assessment was based on Syltherm 800 as base fluid, whereas the thermal properties of this fluid were taken at temperature $575 \mathrm{~K}$, while the thermal properties of the nanoparticle have been varied under the range change based on the common nanoparticle thermal properties. Actually, the common value of the specific heat is less than specific heat value of the base fluid while it has higher values in terms of the density and thermal conductivity. This assessment was performed by varying two nanoparticle thermal properties while fixing the remaining one with $6000 \mathrm{~kg} \mathrm{~m}^{-3}, 551 \mathrm{~J} \mathrm{~kg}^{-1} \mathrm{~K}^{-1}$, and $33 \mathrm{~W} \mathrm{~m}^{-1} \mathrm{~K}^{-1}$ for density, specific heat, and thermal conductivity as fixed values, respectively. Figure $19 \mathrm{a}, \mathrm{b}$ shows that the thermal conductivity has a negligible effect at values much higher than $15 \mathrm{~W} \mathrm{~m}^{-1} \mathrm{~K}^{-1}$. This behavior is justified with Fig. 19c which showed a constant nanofluid thermal conductivity while nanoparticle thermal conductivity is exceeding $15 \mathrm{~W} \mathrm{~m}^{-1} \mathrm{~K}^{-1}$, which leads to no increase in the thermal efficiency beyond this value.

On the other hand, Fig. 20a presents the thermal efficiency variation under variable specific heat and different densities of the nanoparticle; the gradient direction-black arrows-showed that the variation of the specific heat has higher effect at higher density values, while the variation of the density has higher effect at higher specific heat values, where they are close to the base fluid specific heat values. This result agrees with Fig. 20b which assessed the thermal efficiency under the variation of both nanofluid specific heat
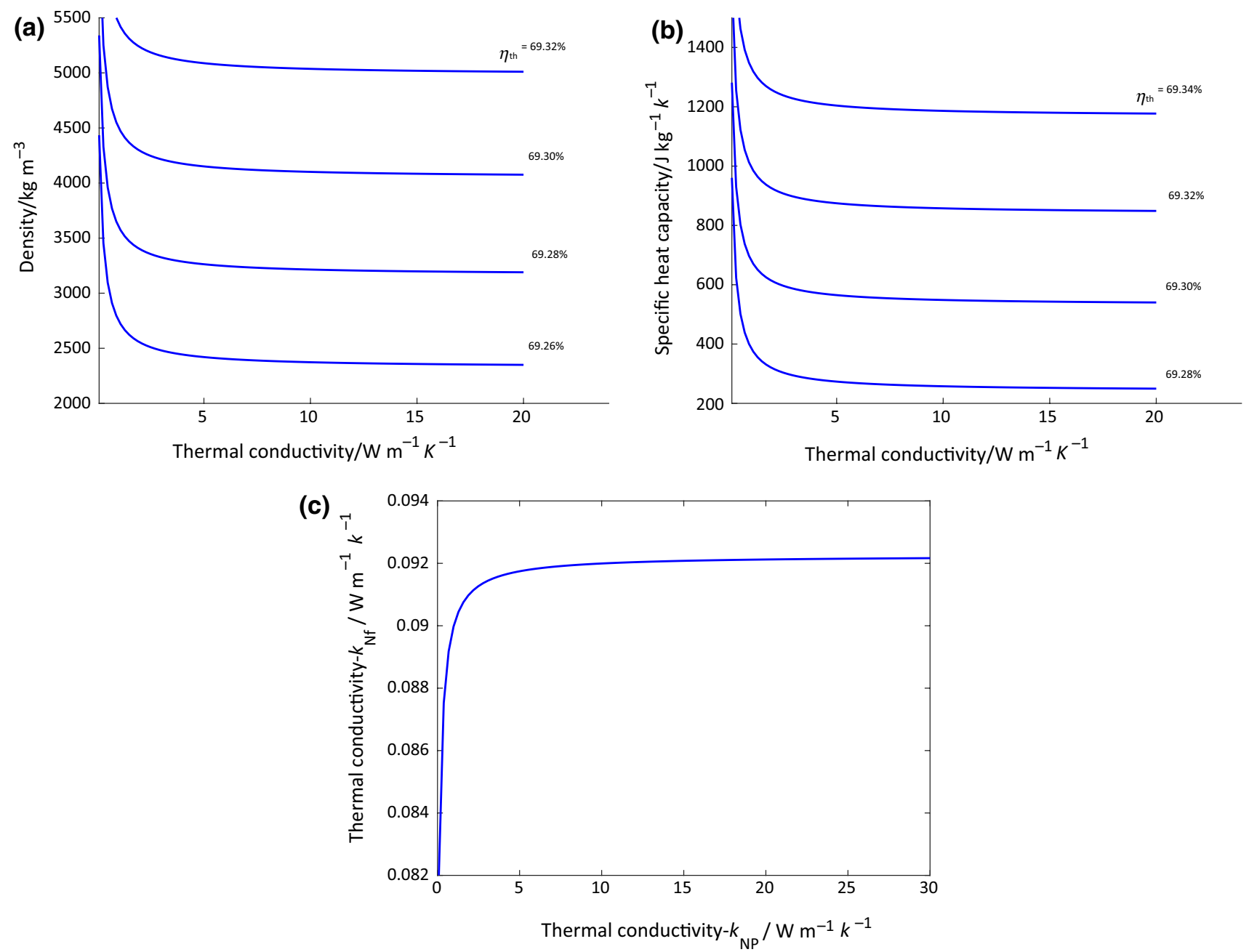

Fig. 19 Thermal efficiency assessment for a different nanoparticle thermal conductivity with various densities. b Different nanoparticle thermal conductivity with various specific heat capacities. c Different nanofluid thermal conductivity 
Fig. 20 Thermal efficiency assessment for a different nanoparticle specific heats with various densities. b Different nanofluid specific heats with various densities
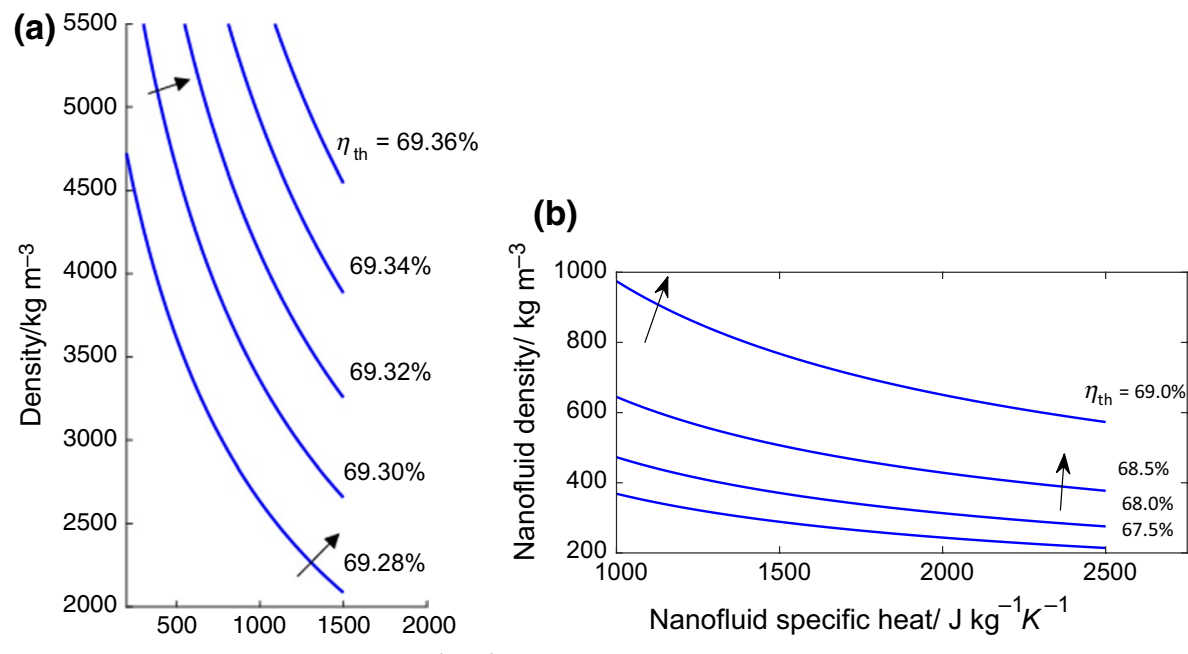

Specific heat capacity/ $\mathrm{J} \mathrm{kg}^{-1} \mathrm{~K}^{-1}$ and density. Finally, higher density and specific heat values produced higher efficiencies, while the density variation has a higher effect at high specific heat values. Also, most of the nanoparticles have specific heat values lower than the base fluid one. From the latter two, selecting a base fluid-nanoparticle combination, it is recommended to select base fluid and nanoparticle with comparable specific heat values, while keeping the focus on selecting a nanoparticle with higher density values to build both thermal and cost-efficient PTC system.

Most of the common nanoparticles have thermal properties that do not meet the desired one. The obstacle can be outwitted by selecting two nanoparticles such that their combination produces the desired properties, which clearly shown in this research study where it is proved that hybrid nanoparticle obtained higher efficiency enhancement than the mono nanoparticle.

\section{Conclusions}

In this paper, thermal analysis of using various HNFs and mono nanofluids compared with thermal oil (Syltherm 800) is examined in a PTC-type LS2. The analytical expression that was taken from the literature improved using MATLAB Symbolic code to cover thermal performance resulted from using two HNFs: $\mathrm{Al}_{2} \mathrm{O}_{3}$ and $\mathrm{CeO}_{2} /$ Syltherm 800, and $\mathrm{Al}_{2} \mathrm{O}_{3}$ and $\mathrm{CuO} /$ Syltherm 800, and three mono nanofluids: $\mathrm{Al}_{2} \mathrm{O}_{3}$, $\mathrm{CeO}_{2}$, and $\mathrm{CuO}$ /Syltherm 800. Furthermore, the analysis was presented under variable temperature ranging from $300 \mathrm{~K}$ to $600 \mathrm{~K}$ and total volume concentration $4 \%$ for different nanofluids. Finally, the assessment of thermal efficiency varies according to the variable nanoparticle thermal properties which were investigated at a chosen temperature equal to $575 \mathrm{~K}$. The main findings in the results were summarized in the following points:

- A positive promising enhancement effect in the thermal efficiency was reached by using various nanofluids especially at high inlet temperature with a significant increase using HNFs compared with mono nanofluids. The maximum thermal efficiency enhancement occurred was $1.09 \%$ using $\mathrm{Al}_{2} \mathrm{O}_{3}$ and $\mathrm{CeO}_{2}$, while it reached $1.08 \%$, $0.4705 \%, 0.4499 \%$, and $0.4045 \%$ for $\mathrm{Al}_{2} \mathrm{O}_{3}$ and Cuo, $\mathrm{CeO}_{2}, \mathrm{CuO}$, and $\mathrm{Al}_{2} \mathrm{O}_{3}$, respectively.

- Exergy efficiency enhancement occurred for various nanofluids particularly for hybrid nanofluids at high inlet temperature. Mainly, the maximum exergy enhancement occurred using $\mathrm{Al}_{2} \mathrm{O}_{3}$ and $\mathrm{CeO}_{2}$ reached $1.03 \%$, while the maximum mono nanofluid exergy enhancement occurred by $\mathrm{CeO}_{2}$ equal $0.4389 \%$ at the inlet temperature $600 \mathrm{~K}$.

- Although the pressure drop was increased by all nanofluids, HNFs had a positive effect by introducing lower values compared with some mono nanofluids which lead to a decrease in the required pump power.

- Heat transfer coefficient and Nusselt enhancement were presented to explain their effects in increasing thermal and exergy efficiency. The maximum heat transfer coefficient and Nusselt number enhancement occurred using $\mathrm{HNF}$ of $\mathrm{Al}_{2} \mathrm{O}_{3}$ and $\mathrm{CeO}_{2}$, and it reached $200.7 \%$ and $167.8 \%$, respectively, compared with $\mathrm{Al}_{2} \mathrm{O}_{3}$ and Cuo which is enhanced by $199.2 \%$ and $166.3 \%$, respectively.

- The effect of the thermal properties for the nanoparticle on the thermal efficiency was assessed. Presented behavior of those assessments provided a clear vision of the nanoparticle thermal properties needed to reach the desired thermal efficiency especially in terms of density and specific heat. 


\section{Limitations and recommendations}

The results of thermal and exergy efficiency are acceptable despite the obtained slight increase which can be justified according to the small heat losses obtained as a result of using high-performance commercial PTC, particularly when using evacuated tube and high concentration ratio as in this research. In addition, the system reliability clarifies from the obtained higher efficiency enhancement at high inlet temperatures because of both increased heat losses and high augmentation in Nusselt number and convective heat transfer. According to that, this type of research gives a good indication about the enhancement effect of using hybrid nanofluid compared with mono nanofluid in thermal and exergy efficiency. Moreover, this type of research still needs more intensive research especially that used HNF to examine thermal efficiency of the PTC. Therefore, the following recommendation was set to enrich this field:

- Economic effects of the nanoparticles price and cost of preparation nanofluid synchronizing with the obtained thermal and exergy efficiency enhancement need especial work to assist their efficient in PTC application.

- Obtained thermal efficiency and heat performance augmentation need intensive work to simulate a semiexperimental work, which is based on evaluating the solution according to the use of experimental correlations for thermal properties of the tested nanofluid.

- Experimental work using hybrid nanofluid or mono nanofluid to improve thermal performance of the domestic PTC needs intensive work to assist thermal enhancement performance of this type.

Acknowledgements Open access funding provided by Budapest University of Technology and Economics (BME).

Open Access This article is licensed under a Creative Commons Attribution 4.0 International License, which permits use, sharing, adaptation, distribution and reproduction in any medium or format, as long as you give appropriate credit to the original author(s) and the source, provide a link to the Creative Commons licence, and indicate if changes were made. The images or other third party material in this article are included in the article's Creative Commons licence, unless indicated otherwise in a credit line to the material. If material is not included in the article's Creative Commons licence and your intended use is not permitted by statutory regulation or exceeds the permitted use, you will need to obtain permission directly from the copyright holder. To view a copy of this licence, visit http://creativecommons.org/licenses/by/4.0/.

\section{References}

1. Kassem A, Al-Haddad K, Komljenovic D, Schiffauerova A. A value tree for identification of evaluation criteria for solar thermal power technologies in developing countries. J Sustain Energy Technol Assess. 2016;16:18-32.

2. Panwar N, Kaushik S, Kothari S. Role of renewable energy sources in environmental protection: a review. J Renew Sustain Energy Rev. 2011;15(3):1513-24.

3. Súri M, Huld TA, Dunlop ED, Ossenbrink HA. Potential of solar electricity generation in the European Union member states and candidate countries. J Solar Energy. 2007;81(10):1295-305.

4. Üçtuğ FG, Azapagic A. Environmental impacts of small-scale hybrid energy systems: coupling solar photovoltaics and lithiumion batteries. J Sci Total Environ. 2018;643:1579-89.

5. Karunathilake H, Perera P, Ruparathna R, Hewage K, Sadiq R. Renewable energy integration into community energy systems: a case study of new urban residential development. J J Clean Prod. 2018;173:292-307.

6. Leong K, Ong HC, Amer N, Norazrina M, Risby M, Ahmad KK. An overview on current application of nanofluids in solar thermal collector and its challenges. J Renew Sustain Energy Rev. 2016;53:1092-105.

7. Wang R, Xu Z, Pan Q, Du S, Xia Z. Solar driven air conditioning and refrigeration systems corresponding to various heating source temperatures. J Appl Energy. 2016;169:846-56.

8. Farjana SH, Huda N, Mahmud MP, Saidur R. Solar process heat in industrial systems-A global review. J Renew Sustain Energy Rev. 2018;82:2270-86.

9. Pytilinski J. Solar energy installations for pumping irrigation water. J Solar Energy. 1978;21(4):255-62.

10. Hafez A, Attia A, Eltwab H, ElKousy A, Afifi A, AbdElhamid A, et al. Design analysis of solar parabolic trough thermal collectors. J Renew Sustain Energy Rev. 2018;82:1215-60.

11. Sajid MU, Ali HM. Recent advances in application of nanofluids in heat transfer devices: a critical review. J Renew Sustain Energy Rev. 2019;103:556-92.

12. Bellos E, Tzivanidis C, Tsimpoukis D. Enhancing the performance of parabolic trough collectors using nanofluids and turbulators. J Renew Sustain Energy Rev. 2018;91:358-75.

13. Babar H, Ali HM. Towards hybrid nanofluids: preparation, thermophysical properties, applications, and challenges. J Mol Liq. 2019;281:598-633.

14. Mahian O, Kolsi L, Amani M, Estellé P, Ahmadi G, Kleinstreuer $\mathrm{C}$, et al. Recent advances in modeling and simulation of nanofluid flows-part I: fundamental and theory. J Phys Rep. 2018;790:1-48.

15. Mahian O, Kolsi L, Amani M, Estellé P, Ahmadi G, Kleinstreuer $\mathrm{C}$, et al. Recent advances in modeling and simulation of nanofluid flows-part II: applications. J Phys Rep. 2018;791:1-59.

16. Olia H, Torabi M, Bahiraei M, Ahmadi MH, Goodarzi M, Safaei MR. Application of nanofluids in thermal performance enhancement of parabolic trough solar collector: state-of-the-art. J Appl Sci. 2019;9(3):463.

17. Ghasemi SE, Ranjbar AA. Thermal performance analysis of solar parabolic trough collector using nanofluid as working fluid: a CFD modelling study. J Mol Liq. 2016;222:159-66.

18. Bellos E, Tzivanidis C. Optimization of a solar-driven trigeneration system with nanofluid-based parabolic trough collectors. J Energies. 2017;10(7):848.

19. Allouhi A, Amine MB, Saidur R, Kousksou T, Jamil A. Energy and exergy analyses of a parabolic trough collector operated with nanofluids for medium and high temperature applications. J Energy Convers Manag. 2018;155:201-17.

20. Mwesigye A, Huan Z, Meyer JP (eds). Thermal performance of a receiver tube for a high concentration ratio parabolic trough system and potential for improved performance with Syltherm800$\mathrm{CuO}$ nanofluid. In: ASME 2015 International mechanical engineering congress and exposition;2015: American Society of Mechanical Engineers. 
21. Mwesigye A, Huan Z, Meyer JP. Thermal performance and entropy generation analysis of a high concentration ratio parabolic trough solar collector with Cu-Therminol ${ }^{\circledR}$ VP-1 nanofluid. J Energy Convers Manag. 2016;120:449-65.

22. Coccia G, Di Nicola G, Colla L, Fedele L, Scattolini M. Adoption of nanofluids in low-enthalpy parabolic trough solar collectors: numerical simulation of the yearly yield. J Energy Convers Manag. 2016;118:306-19.

23. Bellos E, Tzivanidis C. Thermal efficiency enhancement of nanofluid-based parabolic trough collectors. J J Therm Anal Calorim. 2019;135(1):597-608.

24. Subramani J, Nagarajan P, Mahian O, Sathyamurthy R. Efficiency and heat transfer improvements in a parabolic trough solar collector using $\mathrm{TiO}_{2}$ nanofluids under turbulent flow regime. J Renew Energy. 2018;119:19-31.

25. Minea AA. Challenges in hybrid nanofluids behavior in turbulent flow: recent research and numerical comparison. J Renew Sustain Energy Rev. 2017;71:426-34.

26. Huminic G, Huminic A. Hybrid nanofluids for heat transfer applications-a state-of-the-art review. J Int J Heat Mass Transf. 2018;125:82-103.

27. Suresh S, Venkitaraj K, Selvakumar P, Chandrasekar M. Synthesis of $\mathrm{Al}_{2} \mathrm{O}_{3}-\mathrm{Cu}$ /water hybrid nanofluids using two step method and its thermo physical properties. J Colloids Surfaces A Physicochem Eng Asp. 2011;388(1-3):41-8.

28. Suresh S, Venkitaraj K, Hameed MS, Sarangan J. Turbulent heat transfer and pressure drop characteristics of dilute water based $\mathrm{Al}_{2} \mathrm{O}_{3}-\mathrm{Cu}$ hybrid nanofluids. J Nanosci Nanotechnol. 2014;14(3):2563-72.

29. Suresh $\mathrm{S}$, Venkitaraj K, Selvakumar P, Chandrasekar M. Effect of $\mathrm{Al}_{2} \mathrm{O}_{3}-\mathrm{Cu}$ /water hybrid nanofluid in heat transfer. J Exp Therm Fluid Sci. 2012;38:54-60.

30. Hamid KA, Azmi W, Nabil M, Mamat R, Transfer M. Experimental investigation of nanoparticle mixture ratios on $\mathrm{TiO}_{2}-\mathrm{SiO}_{2}$ nanofluids heat transfer performance under turbulent flow. Int $\mathrm{J}$ Heat Mass Transf. 2018;118:617-27.

31. Bellos E, Tzivanidis CJD. Thermal analysis of parabolic trough collector operating with mono and hybrid nanofluids. J Sustain Energy Technol Assess. 2018;26:105-15.

32. Minea AA, El-Maghlany WM. Influence of hybrid nanofluids on the performance of parabolic trough collectors in solar thermal systems: recent findings and numerical comparison. J Renew Energy. 2018;120:350-64.

33. Sekhar TVR, Prakash R, Nandan G, Muthuraman M. Performance enhancement of a renewable thermal energy collector using metallic oxide nanofluids. J Micro Nano Lett. 2018;13(2):248-51.

34. Sharafeldin M, Gróf G. Experimental investigation of flat plate solar collector using $\mathrm{CeO}_{2}$-water nanofluid. J Energy Convers Manag. 2018;155:32-41.

35. Bellos E, Tzivanidis C. Analytical expression of parabolic trough solar collector performance. J Des. 2018;2(1):9.
36. Dudley VE, Evans LR, Matthews CW. Test results, industrial solar technology parabolic trough solar collector: Sandia National Labs., Albuquerque, NM (United States) 1995.

37. Kotas TJ. The exergy method of thermal plant analysis. Amsterdam: Elsevier; 2013.

38. Bellos E, Tzivanidis C, Antonopoulos K, Gkinis G. Thermal enhancement of solar parabolic trough collectors by using nanofluids and converging-diverging absorber tube. J Renew Energy. 2016;94:213-22.

39. Petela R. Exergy of undiluted thermal radiation. J Solar Energy. 2003;74(6):469-88.

40. Bellos E, Tzivanidis C. A detailed exergetic analysis of parabolic trough collectors. J Energy Convers Manag. 2017;149:275-92.

41. Incropera FP, Lavine AS, Bergman TL, DeWitt DP. Fundamentals of heat and mass transfer. Hoboken: Wiley; 2007.

42. Rasih RA, Sidik NAC, Samion S. Recent progress on concentrating direct absorption solar collector using nanofluids. J Therm Anal Calorim. 2019;137:903-22.

43. Takabi B, Salehi S. Augmentation of the heat transfer performance of a sinusoidal corrugated enclosure by employing hybrid nanofluid. J Adv Mech Eng. 2014;6:147059.

44. Maxwell JC. A treatise on electricity and magnetism. Oxford: Clarendon Press; 1873.

45. Brinkman $H$. The viscosity of concentrated suspensions and solutions. J Chem Phys. 1952;20(4):571.

46. Mwesigye A, Huan Z. Thermal and thermodynamic performance of a parabolic trough receiver with Syltherm $800-\mathrm{Al}_{2} \mathrm{O}_{3}$ nanofluid as the heat transfer fluid. J Energy Procedia. 2015;75:394-402.

47. Minea AA. Hybrid nanofluids based on $\mathrm{Al}_{2} \mathrm{O}_{3}, \mathrm{TiO}_{2}$ and $\mathrm{SiO}_{2}$ : numerical evaluation of different approaches. $\mathrm{J}$ Int $\mathbf{J}$ Heat Mass Transf. 2017;104:852-60.

48. Pak BC, Cho YI. Hydrodynamic and heat transfer study of dispersed fluids with submicron metallic oxide particles. J Exp Heat Transf Int J. 1998;11(2):151-70.

49. Okonkwo EC, Essien EA, Abid M, Kavaz D, Ratlamwala TA. Thermal performance analysis of a parabolic trough collector using water-based green-synthesized nanofluids. J Solar Energy. 2018;170:658-70.

50. Basbous N, Taqi M, Janan MA, (eds). Thermal performances analysis of a parabolic trough solar collector using different nanofluids. In: 2016 International renewable and sustainable energy conference (IRSEC); 2016. IEEE.

Publisher's Note Springer Nature remains neutral with regard to jurisdictional claims in published maps and institutional affiliations. 